10,19

\title{
Изменение параметров образования вакансий и самодиффузии в кристалле с температурой и давлением
}

\author{
(C) М.Н. Магомедов
}

Институт проблем геотермии и возобновляемой энергетики филиал Объединенного института высоких температур РАН, Махачкала, Россия

E-mail: mahmag4@mail.ru

Поступила в Редакцию 10 ноября 2021 г.

В окончательной редакции 10 ноября 2021 r.

Принята к публикации 18 ноября 2021 г.

Предложен аналитический метод расчета параметров образования электронейтральных вакансий и самодиффузии атомов в однокомпонентном кристалле. Метод основан на парном 4-параметрическом потенциале межатомного взаимодействия Ми-Леннард-Джонса. Метод позволяет рассчитывать все параметры активационных процессов: энергию Гиббса, энтальпию, энтропию и объем, как для процесса образования вакансии, так и для процесса самодиффузии. Метод применим при любых давлениях $(P)$ и температурах $(T)$. Рассчитана температурная зависимость параметров активационных процессов золота от $T=10$ до $1330 \mathrm{~K}$ вдоль двух изобар: $P=0$ и $24 \mathrm{GPa}$. Показано, что при низких температурах из-за квантовых закономерностей активационные параметры сильно зависят от температуры, причем энтропия активационных процессов в этой области отрицательная. В области высоких температур вероятность образования вакансии и коэффициент самодиффузии переходят в классические зависимости Аррениуса со слабо зависящей от температуры энтальпией и с положительным значением энтропии активационного процесса. Получено хорошее согласие с известными из литературы оценками активационных параметров для золота. Обсуждены значения активационных параметров при $T=0 \mathrm{~K}$.

Ключевые слова: вакансия, самодиффузия, межатомный потенциал, золото, уравнение состояния, тепловое расширение.

DOI: $10.21883 /$ FTT.2022.04.52189.240

\section{1. Введение}

Изучение активационных процессов (т. е. образования электронейтральных вакансий и самодиффузии) в кристалле однокомпонентного вещества проводятся давно, и результаты этих работ представлены в обзорах [1-6]. Энтальпии образования вакансии $\left(h_{\mathrm{v}}\right)$ и самодиффузии $\left(h_{\mathrm{d}}\right)$ были измерены различными методами, что позволило получить объективную оценку этих энергетических параметров активационных процессов.

Но экспериментальное изучение этих процессов проведено только в области высоких температур $(T \gg \Theta)$ и низких давлений $(P=1 \mathrm{~atm})$, где эти активационные процессы оказывают максимальное влияние на свойства кристалла и потому величину активационных параметров можно экспериментально оценить. Здесь $\Theta-$ температура Дебая. Вместе с тем, если энтальпию образования вакансий и самодиффузии $\left(h_{i}\right)$ еще можно достоверно измерить в области высоких температур, то объем активационного процесса $\left(v_{i}\right)$ оценивается очень приближенно даже при $T \gg \Theta$ [7]. Экспериментальных методов для оценки энтропии $\left(s_{i}\right)$ активационных процессов пока нет $[8,9](i=\mathrm{v}, \mathrm{d})$.

Что касается теоретического изучения параметров активационных процессов, то было предложено много моделей как для образования электронейтральных ва- кансий, так и для самодиффузии в кристалле [8-10]. Однако ни одна из предложенных методик расчета (ни аналитическая, ни компьютерная) не позволила описать как изобарную температурную зависимость, так и изотермическую барическую зависимость всех параметров активационного процесса в кристалле однокомпонентного вещества.

Между тем многие фундаментальные вопросы до сих пор не имеют ясного ответа:

Как происходит переход от высокотемпературной диффузии (описываемой формулой Аррениуса) к квантовой диффузии при низких температурах, где уравнение Аррениуса уже не работает?

Какова изобарная (при $P=1 \mathrm{~atm})$ температурная зависимость функций $s_{i}(T)$ и $v_{i}(T)$, начиная от $T=0 \mathrm{~K}$ и до температуры плавления кристалла?

Как изменяются данные изобарные зависимости функций $s_{i}(T)$ и $v_{i}(T)$ при увеличении давления на изобаре?

В связи с этим в данной работе предложен аналитический метод для изучения термических и барических зависимостей активационных процессов в кристалле однокомпонентного вещества. На примере кристалла золота с помощью этого метода впервые рассчитаны зависимости всех активационных параметров от температуры, начиная от $T=10 \mathrm{~K}$ и до температуры плавления. При этом все расчеты были выполнены вдоль 
двух изобар: при $P=0 \mathrm{GPa} \cong 1 \mathrm{~atm}$ (где были получены экспериментальные оценки) и при $P=24 \mathrm{GPa}$.

\section{2. Метод расчета вероятности образования вакансии}

Представим монокристалл однокомпонентного вещества из $N$ атомов в виде структуры из $N+N_{\mathrm{v}}$ ячеек одинакового размера, в которой $N_{\mathrm{v}}$ ячеек вакантны и однородно распределены по объему кристалла $V$. При этом будем полагать, что атомы в системе могут находиться в двух состояниях: в локализованном (L-), и в делокализованном (D-). B L-состоянии атом локализован в ячейке, образованной ближайшими соседями, и имеет только колебательные степени свободы. В D-состоянии атому доступен весь объем системы, и он имеет только трансляционные степени свободы. Атомы в Lи D-состоянии для краткости будем называть L- и D-атомами.

Объем системы равен сумме объемов $v_{\mathrm{a}}$, приходящихся на одну (занятую либо вакантную) атомную ячейку, форму которой считаем сферической

$$
\begin{gathered}
V=\frac{\pi}{6 k_{\mathrm{p}}}\left(N+N_{\mathrm{v}}\right) \cdot c^{3}=\frac{v_{\mathrm{a}}}{k_{\mathrm{p}}} \frac{N}{\left(1-\phi_{\mathrm{v}}\right)}, \\
v_{\mathrm{a}}=\frac{\pi}{6} \cdot c^{3}=\frac{V}{N} \cdot k_{\mathrm{p}} \cdot\left(1-\phi_{\mathrm{v}}\right), \\
c_{\mathrm{o}}=\left(\frac{6 k_{\mathrm{p}} V}{\pi N}\right)^{1 / 3}=\left[\frac{6 v_{\mathrm{a}}\left(\phi_{\mathrm{v}}=0\right)}{\pi}\right]^{1 / 3} .
\end{gathered}
$$

Здесь $\phi_{\mathrm{v}}=N_{\mathrm{v}} /\left(N+N_{\mathrm{v}}\right)$ - вероятность обнаружить вакантную ячейку в системе, $c=c_{\mathrm{o}}\left(1-\phi_{\mathrm{v}}\right)^{1 / 3}-$ расстояние между центрами ближайших ячеек, $k_{\mathrm{p}}-$ коэффициент упаковки структуры из $N+N_{\mathrm{v}}$ сферических ячеек, $c_{\text {o }}$ - расстояние между центрами ближайших ячеек в исходной (не срелаксировавшей в активированное вакансиями состояние) безвакансионной (при $N_{\mathrm{v}}=0$ ) виртуальной решетке (на это указывает индекс „о“).

При отсутствии различных градиентов для вероятности обнаружить атом в шаровом слое толщиной $d r$ на расстоянии $r$ от центра ячейки можно использовать выражение

$$
\phi_{\mathrm{c}}(r) d r=C_{\mathrm{c}} \cdot \exp \left(-\frac{r^{2}}{2\left\langle r^{2}\right\rangle}\right) d r
$$

где $C_{\mathrm{c}}$ - постоянная нормировки, $\left\langle r^{2}\right\rangle-$ среднеквадратичное отклонение атома от центра ячейки.

Разделим шаровой слой на $k_{n}^{\mathrm{o}}$ участков, где $k_{n}^{\mathrm{o}}-$ число всех ячеек (как занятых, так и вакантных), ближайших к данному атому. Представляя атом как сгусток плотности вероятности и рассматривая величину $\phi_{\mathrm{c}}(r) d r$ как вероятность одновременного смещения атома во всех $k_{n}^{o} / 2$ радиальных направлениях, для вероятности смещения атома в одном $j$-м направлении можно принять

$$
\phi_{j}(r) d r=\frac{2}{\left(\pi k_{n}^{\mathrm{o}}\left\langle r^{2}\right\rangle_{j}\right)^{1 / 2}} \cdot \exp \left(-\frac{r^{2}}{2\left\langle r^{2}\right\rangle_{j}}\right) d r .
$$

Будем считать, что атом может покинуть ячейку, если амплитуда его колебания в ячейке превысит величину $c_{j o} / 2$, где $c_{j \mathrm{o}}-$ расстояние между центрами ближайших ячеек в $j$-м направлении в исходной безвакансионной виртуальной решетке (поэтому индекс „о“). Тогда можно определить вероятность образования вакансии как среднее арифметическое из вероятностей покинуть ячейку в каком-либо из $k_{n}^{o} / 2$ направлений. Для изотропной модели это приводит к выражению следующего вида $[11,12]$ :

$$
\begin{aligned}
\phi_{\mathrm{v}}(\rho, T) & =\frac{N_{\mathrm{v}}(\rho, T)}{N+N_{\mathrm{v}}}=\frac{2}{\pi^{1 / 2}} \int_{c_{\mathrm{o}} /\left[2\left(k_{n}^{\mathrm{o}}\left\langle r^{2}\right\rangle\right)^{1 / 2}\right]}^{\infty} \exp \left(-t^{2}\right) d t \\
& =1-\operatorname{erf}\left(\frac{c}{2\left(k_{n}^{\left.\mathrm{o}\left\langle r^{2}\right\rangle\right)^{1 / 2}}\right),}\right.
\end{aligned}
$$

где $\rho=N / V$ - плотность числа атомов; интеграл вероятностей имеет вид [13]:

$$
\operatorname{erf}(x)=\frac{2}{\pi^{1 / 2}} \int_{0}^{x} \exp \left(-t^{2}\right) d t
$$

Определяя функцию $\left\langle r^{2}\right\rangle$ для системы из L- и $\mathrm{D}$-атомов, необходимо учесть, что характер их движения различен. Так как L-атомы имеют только колебательные степени свободы, a D-атомы имеют (по определению) только трансляционные степени свободы, то представим функцию $\left\langle r^{2}\right\rangle$ в виде

$$
\left\langle r^{2}\right\rangle=\left(1-x_{\mathrm{d}}\right)\left\langle r^{2}\right\rangle_{\mathrm{L}}+x_{\mathrm{d}}\left\langle r^{2}\right\rangle_{\mathrm{D}}
$$

Здесь $\left\langle r^{2}\right\rangle_{\mathrm{L}}$ и $\left\langle r^{2}\right\rangle_{\mathrm{D}}$ - среднеквадратичное смещение атома в L- и D-состоянии, соответственно, $x_{\mathrm{d}}$ - доля атомов, находящихся в D-состоянии.

Используя для определения функции $\left\langle r^{2}\right\rangle_{\mathrm{L}}$ модель гармонического осциллятора [14] и считая, что все $\mathrm{L}$-атомы колеблются с одинаковой частотой (модель Эйнштейна), получим

$$
\left\langle r^{2}\right\rangle_{\mathrm{L}}=\frac{\hbar^{2} k_{\mathrm{B}} T}{m\left(k_{\mathrm{B}} \Theta_{\mathrm{Eo}}\right)^{2} f_{y}\left(\Theta_{\mathrm{Eo}} / T\right)},
$$

где $\hbar$ - постоянная Планка, $k_{\mathrm{B}}$ - постоянная Больцмана, $m$ - масса атома, $\Theta_{\text {Ео }}$ - температура Эйнштейна в безвакансионной решетке (поэтому индекс „о“), функция $f_{y}\left(y_{w}\right)$ появляется из-за учета квантовых эффектов и имеет вид

$$
f_{y}\left(y_{w}\right)=\frac{2}{y_{w}} \cdot \frac{\left[1-\exp \left(-y_{w}\right)\right]}{\left[1+\exp \left(-y_{w}\right)\right]}, \quad y_{w}=\frac{\Theta_{\mathrm{Eo}}}{T} .
$$


Для определения величины $\left\langle r^{2}\right\rangle_{\mathrm{D}}$ необходимо знать размер той области, которая доступна для движения D-атома в решетке за время, равное периоду колебания L-атома. Так как система однородна и D-атому доступен весь ее объем, то конфигурационный интеграл для D-атома в решетке из $N+N_{\mathrm{v}}$ ячеек равного размера можно представить в виде

$$
\begin{aligned}
\text { In } & =\frac{1}{V} \int_{V} \exp \left(-\frac{U}{k_{\mathrm{B}} T}\right) d V \\
& =\frac{N+N_{\mathrm{v}}}{V} \int_{V /\left(N+N_{\mathrm{v}}\right)} \exp \left(-\frac{U}{k_{\mathrm{B}} T}\right) 4 \pi r^{2} d r,
\end{aligned}
$$

где $U-$ потенциальная энергия взаимодействия рассматриваемого D-атома с его окружением.

Переходя к переменной $t=r / c_{0}$, с учетом (2) получим

$$
\text { In }=24 k_{\mathrm{p}} \cdot \int_{0}^{\alpha_{3}} \exp \left(-\frac{U}{k_{\mathrm{B}} T}\right) t^{2} d t,
$$

Здесь верхний предел интегрирования $\alpha_{3}$ определяет радиус (в относительных единицах) области для движения D-атома в решетке из $N+N_{\mathrm{v}}$ одинаковых сферических ячеек. Его найдем из граничного условия, которому должна удовлетворять функция In:

$$
\lim _{U /\left(k_{\mathrm{B}} T\right)=0} I n=1 .
$$

Отсюда получаем значение: $\alpha_{3}=0.5 / k_{\mathrm{p}}^{1 / 3}$. Поэтому диаметр области доступности для D-атома в решеточной структуре за период колебания L-атома будет равным

$$
\lambda_{3}=2 c_{\mathrm{o}} \alpha_{3}=c_{\mathrm{o}} / k_{\mathrm{p}}^{1 / 3} .
$$

$\mathrm{C}$ другой стороны, атом переходит из L- в D-состояние, когда его скорость позволяет ему за полпериода колебания в L-состоянии $(\tau / 2)$ пройти расстояние, равное радиусу области доступности для D-атома в исходной безвакансионной (не срелаксировавшей в активированное состояние) решеточной структуре: $\lambda_{3} / 2$. Таким образом, скорость атома при переходе из L- в D-состояние должна превышать величину $v_{\min }=\left(\lambda_{3} / 2\right) /(\tau / 2)$. Так как в силу изотропности модели только треть смещений совершается в выбранном направлении, то для среднеквадратичного смещения D-атома за время полного периода колебания L-атома можно принять

$$
\left\langle r^{2}\right\rangle_{\mathrm{D}}=\frac{\left(v_{\min } \tau\right)^{2}}{3}=\frac{1}{3}\left(\frac{c_{\mathrm{o}}}{k_{\mathrm{p}}^{1 / 3}}\right)^{2} .
$$

Исходя из формул (3)-(9), получаем выражение для вероятности образования вакансии в виде $[11,12]$ :

$$
\begin{aligned}
\phi_{\mathrm{v}} & =1-\operatorname{erf}\left(\frac{c_{\mathrm{o}}}{2\left(k_{\mathrm{p}}^{\mathrm{o}}\left\langle r^{2}\right\rangle\right)^{1 / 2}}\right) \\
& =1-\operatorname{erf}\left[\left(\frac{E_{\mathrm{v}}}{k_{\mathrm{B}} T}\right)^{1 / 2}\right]=\operatorname{erfc}\left[\left(\frac{E_{\mathrm{v}}}{k_{\mathrm{B}} T}\right)^{1 / 2}\right] .
\end{aligned}
$$

Здесь $E_{\mathrm{v}}$ - энергия создания вакантной ячейки в безвакансионной решетке, которая определяется выражением

$$
E_{\mathrm{v}}=\frac{E_{\mathrm{L}}}{1+x_{\mathrm{d}}\left[\left(C_{\mathrm{D}} E_{\mathrm{L}} / k_{\mathrm{B}} T\right)-1\right]},
$$

где введены обозначения

$$
\begin{gathered}
E_{\mathrm{L}}=\frac{c_{\mathrm{o}}^{2} k_{\mathrm{B}} T}{4 k_{n}^{\mathrm{o}}\left\langle r^{2}\right\rangle_{\mathrm{L}}}=\frac{m}{k_{n}^{\mathrm{o}}}\left(\frac{c_{\mathrm{o}}^{2} k_{\mathrm{B}} \Theta_{\mathrm{Eo}}}{2 \hbar}\right)^{2} f_{y}\left(\frac{\Theta_{\mathrm{Eo}}}{T}\right), \\
C_{\mathrm{D}}=\frac{4 k_{n}^{\mathrm{o}}}{3 k_{\mathrm{p}}^{2 / 3}} .
\end{gathered}
$$

В случае $T>\Theta_{\text {Eо }}$ функция $E_{\mathrm{L}}$ не зависит от температуры, и вплоть до температуры плавления выполняется $E_{\mathrm{v}}>k_{\mathrm{B}} T$. Тогда выражение (10) можно с хорошей точностью заменить экспоненциальной аррениусовской зависимостью вида [13]:

$$
\begin{aligned}
& \phi_{\mathrm{v}}=1-\operatorname{erf}\left[\left(\frac{E_{\mathrm{v}}}{k_{\mathrm{B}} T}\right)^{1 / 2}\right] \\
& \cong\left(\frac{k_{\mathrm{B}} T}{\pi E_{\mathrm{v}}}\right)^{1 / 2} \exp \left(-\frac{E_{\mathrm{v}}}{k_{\mathrm{B}} T}\right) .
\end{aligned}
$$

Но при $T<\Theta_{\text {Ео }}$ функции $E_{\mathrm{L}}$ и $E_{\mathrm{V}}$ имеют линейную температурную зависимость, что нарушает аррениусовскую температурную зависимость для вероятности образования вакансии. При этом из (14) легко видеть, что выполняется неравенство

$$
\phi_{\mathrm{v}}(\rho, T=0 \mathrm{~K})>0 .
$$

\section{3. Определение вероятности делокализации атома в кристалле}

Для определения доли D-атомов мы используем распределение Максвелла для кинетической энергии атомов, которое справедливо не только для газа, но и для жидкой, аморфной и кристаллической фазы $[15,16]$. Долю D-атомов определим как доля атомов, имеющих кинетическую энергию выше порогового значения $E_{\mathrm{d}}-$ энергии делокализации атома

$$
\begin{aligned}
& x_{\mathrm{d}}(\rho, T)=\frac{N_{\mathrm{d}}(\rho, T)}{N}=\frac{2}{\pi^{1 / 2}} \int_{E_{\mathrm{d}} /\left(k_{\mathrm{B}} T\right)}^{\infty} t^{1 / 2} \exp (-t) d t \\
& =2\left(\frac{E_{\mathrm{d}}}{\pi k_{\mathrm{B}} T}\right)^{1 / 2} \cdot \exp \left(-\frac{E_{\mathrm{d}}}{k_{\mathrm{B}} T}\right)+1-\operatorname{erf}\left[\left(\frac{E_{\mathrm{d}}}{k_{\mathrm{B}} T}\right)^{1 / 2}\right],
\end{aligned}
$$

где $E_{\mathrm{d}}-$ это энергия, необходимая для перехода атома из L- в D-состояние.

Чтобы атом перешел из L-состояния в D-состояние, его скорость должна быть не менее чем $v_{\min }=\lambda_{3} / \tau$, где $\tau-$ период колебания L-атома в ячейке. Именно 
начиная с такой скорости, атом может уйти из ячейки. Так как для эйнштейновской модели кристалла период колебания атома в ячейке равен [14]:

$$
\tau=\frac{2 \pi \hbar}{k_{\mathrm{B}} \Theta_{\mathrm{Eo}}}=\frac{8 \pi \hbar}{3 k_{\mathrm{B}} \Theta_{\mathrm{o}}},
$$

то функцию $E_{\mathrm{d}}$ можно определить в виде [17]:

$$
\begin{aligned}
E_{\mathrm{d}} & =\frac{3}{2} m v_{\min }^{2} \cdot f_{y}\left(y_{w}\right)=\left(\frac{3}{8 \pi^{2}}\right) m\left(\frac{c_{o} k_{\mathrm{B}} \Theta_{\mathrm{Eo}}}{\hbar k_{\mathrm{p}}^{1 / 3}}\right)^{2} f_{y}\left(y_{w}\right) \\
& =C_{\mathrm{LD}} E_{\mathrm{L}}=E_{\mathrm{d} 1} f_{y}\left(y_{w}\right) .
\end{aligned}
$$

Здесь введены обозначения

$$
\begin{gathered}
E_{\mathrm{d} 1}=E_{\mathrm{d}}\left(f_{y}\left(y_{w}\right)=1\right)=\frac{3 m}{8 k_{\mathrm{p}}^{2 / 3}}\left(\frac{3 c_{\mathrm{o}} k_{\mathrm{B}} \Theta_{\mathrm{o}}}{4 \pi \hbar}\right)^{2}, \\
C_{\mathrm{LD}}=\frac{3 k_{n}^{\mathrm{o}}}{2 \pi^{2} k_{\mathrm{p}}^{2 / 3}}=\left(\frac{9}{8 \pi^{2}}\right) C_{\mathrm{D}},
\end{gathered}
$$

где $\Theta-$ температура Дебая, которая связана с температурой Эйнштейна соотношением: $\Theta=(4 / 3) \Theta_{\mathrm{E}}[18$, гл. 13; 19, гл. 2].

Вплоть до температуры плавления $\left(T_{\mathrm{m}}\right)$ для большинства веществ (кроме квантовых кристаллов) выполняется неравенство $E_{\mathrm{d}}>E_{\mathrm{v}}>k_{\mathrm{B}} T_{\mathrm{m}}$. Поэтому неполную гамма-функцию в (15) на всем температурном интервале от $T=0 \mathrm{~K}$ до $T_{\mathrm{m}}$ можно аппроксимировать формулой аррениусовского типа [13]:

$$
\begin{gathered}
x_{\mathrm{d}}(\rho, T)=2\left(\frac{E_{\mathrm{d}}}{\pi k_{\mathrm{B}} T}\right)^{1 / 2} \exp \left(-\frac{E_{\mathrm{d}}}{k_{\mathrm{B}} T}\right)\left[1+\frac{k_{\mathrm{B}} T}{2 E_{\mathrm{d}}}\right. \\
\left.-\left(\frac{k_{\mathrm{B}} T}{2 E_{\mathrm{d}}}\right)^{2}+\ldots\right] \cong 2\left(\frac{E_{\mathrm{d}}}{\pi k_{\mathrm{B}} T}\right)^{1 / 2} \exp \left(-\frac{E_{\mathrm{d}}}{k_{\mathrm{B}} T}\right) .
\end{gathered}
$$

Функция $E_{\mathrm{d}}$ в (19), так же, как и $E_{\mathrm{v}}$ в (14), при

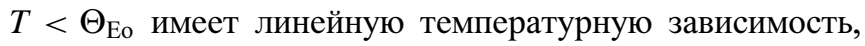
что нарушает аррениусовскую температурную зависимость для вероятности делокализации атома. При этом, из (14) следует неравенство: $x_{\mathrm{d}}(\rho, T=0 \mathrm{~K})>0$.

В наших работах $[11,12,17,20-22]$ было показано, что вышеописанный формализм из (10)-(19) позволяет изучить активационные параметры от $T=0 \mathrm{~K}$ и до перехода в жидкую фазу. Причем, как легко видеть, формализм из $(10)-(19)$ позволяет изучить изменение функций $\phi_{\mathrm{v}}(\rho, T)$ и $x_{\mathrm{d}}(\rho, T)$ как при изохорическом изменении температуры, так и при изотермическом изменении плотности кристалла.

\section{4. Термодинамические параметры активационных процессов}

Термодинамическое определение активационных (образования вакансий и самодиффузии) параметров, осно- ванное на формулах равновесной и обратимой термодинамики [1-6,19], имеет вид

$$
\begin{gathered}
g_{i}=-k_{\mathrm{B}} T \ln \left(A_{i}\right) \\
h_{i}=-\left(\frac{\partial \ln \left(A_{i}\right)}{\partial\left[1 /\left(k_{\mathrm{B}} T\right)\right]}\right)_{P}=g_{i}+T s_{i} \\
s_{i}=-\left(\frac{\partial g_{i}}{\partial T}\right)_{P}=-\left(\frac{\partial g_{i}}{\partial T}\right)_{V}-\alpha_{P} V\left(\frac{\partial g_{i}}{\partial V}\right)_{T}=\frac{h_{i}-g_{i}}{T}, \\
v_{i}=-\left(\frac{\partial g_{i}}{\partial P}\right)_{T}=-\frac{V}{B_{T}}\left(\frac{\partial g_{i}}{\partial V}\right)_{T} .
\end{gathered}
$$

Здесь $g_{i}, h_{i}, s_{i}, v_{i}$ - энергия Гиббса, энтальпия, энтропия и объем активационного процесса (индекс $i=\mathrm{v}$ или $\mathrm{d}$ для образования вакансии $\left(A_{i}=\phi_{\mathrm{v}}\right)$ или для самодиффузии $\left.\left(A_{i}=x_{\mathrm{d}}\right)\right)$, соответственно. Функция $\alpha_{P}=(1 / V)(\partial V / \partial T)_{P}-$ это изобарический коэффициент теплового расширения, $B_{T}=-V(\partial P / \partial V)_{T}$ - изотермический модуль упругости.

Из (10)-(19), предполагая, что характеристическая температура не изменяется при изохорическом нагреве (т. е. при условии $\left.\left(\partial \Theta_{\mathrm{o}} / \partial T\right)_{V}=0\right)$, и принимая приближения (14) и (19), можно получить выражения для энергии Гиббса, энтальпии, энтропии и объема активационного процесса в виде $[11,12,17]$ :

для процесса образования вакансии

$$
\begin{gathered}
g_{\mathrm{v}}=-k_{\mathrm{B}} T \cdot \ln \left(\phi_{\mathrm{v}}\right)=E_{\mathrm{v}}\left[1+\left(\frac{k_{\mathrm{B}} T}{2 E_{\mathrm{v}}}\right) \ln \left(\frac{\pi E_{\mathrm{v}}}{k_{\mathrm{B}} T}\right)\right], \\
h_{\mathrm{v}}=k_{\mathrm{B}} T \phi_{\mathrm{E}}\left\{1-t_{y}+\alpha_{P} T\left[\left(2-t_{y}\right) \gamma_{\mathrm{o}}-\frac{2}{3}\right]\right\}, \\
\frac{s_{\mathrm{v}}}{k_{\mathrm{B}}}=\frac{h_{\mathrm{v}}-g_{\mathrm{v}}}{k_{\mathrm{B}} T}, \\
\frac{v_{\mathrm{v}}}{v_{0}}=\frac{k_{\mathrm{B}} T}{B_{T} v_{0}} \phi_{\mathrm{E}}\left[\left(2-t_{y}\right) \gamma_{\mathrm{o}}-\frac{2}{3}\right],
\end{gathered}
$$

для процесса самодиффузии

$$
\begin{gathered}
g_{d}=-k_{\mathrm{B}} T \cdot \ln \left(x_{\mathrm{d}}\right)=E_{\mathrm{d}}\left[1-\left(\frac{k_{\mathrm{B}} T}{2 E_{\mathrm{d}}}\right) \ln \left(\frac{4 E_{\mathrm{d}}}{\pi k_{\mathrm{B}} T}\right)\right], \\
h_{\mathrm{d}}=E_{\mathrm{d}}\left\{1-t_{y}+\alpha_{P} T\left[\left(2-t_{y}\right) \gamma_{\mathrm{o}}-\frac{2}{3}\right]\right\}, \\
\frac{s_{\mathrm{d}}}{k_{\mathrm{B}}}=\frac{h_{\mathrm{d}}-g_{\mathrm{d}}}{k_{\mathrm{B}} T}=\frac{E_{\mathrm{d}}}{k_{\mathrm{B}} T}\left\{\left(\frac{k_{\mathrm{B}} T}{2 E_{\mathrm{d}}}\right) \ln \left(\frac{4 E_{\mathrm{d}}}{\pi k_{\mathrm{B}} T}\right)-t_{y}\right. \\
\left.+\alpha_{P} T\left[\left(2-t_{y}\right) \gamma_{\mathrm{o}}-\frac{2}{3}\right]\right\}, \\
\frac{v_{\mathrm{d}}}{v_{0}}=\frac{E_{\mathrm{d}}}{B_{T} v_{0}}\left[\left(2-t_{y}\right) \gamma_{\mathrm{o}}-\frac{2}{3}\right] .
\end{gathered}
$$


Здесь $\gamma_{\mathrm{o}}=-\left[\partial \ln \left(\Theta_{\mathrm{Eo}}\right) / \partial \ln (V)\right]_{T}$ - первый параметр Грюнайзена для безвакансионного кристалла, $v_{0}-$ объем, приходящийся на атом при $P=0$ и $T=0 \mathrm{~K}$,

$$
\begin{gathered}
t_{y}\left(y_{w}\right)=-\frac{\partial \ln \left(f_{y}\right)}{\partial \ln \left(y_{w}\right)}=1-\frac{2 y_{w} \exp \left(y_{w}\right)}{\left[\exp \left(2 y_{w}\right)-1\right]}, \\
\phi_{\mathrm{E}}=\left(\frac{E_{\mathrm{v}}}{k_{\mathrm{B}} T}\right)\left[1+x_{\mathrm{d}} C_{\mathrm{D}}\left(\frac{E_{\mathrm{v}}}{k_{\mathrm{B}} T}\right) \frac{E_{\mathrm{d}}}{k_{\mathrm{B}} T} G_{\mathrm{d}}\right], \\
G_{\mathrm{d}}=1-\frac{k_{\mathrm{B}} T}{C_{\mathrm{D}} E_{\mathrm{L}}}-\frac{k_{\mathrm{B}} T}{E_{\mathrm{d}}} .
\end{gathered}
$$

Из выражений (11), (21)-(23) видно, что учет D-атомов (т.е. функции $x_{\mathrm{d}}$ ) уменьшает величины $E_{\mathrm{v}}$ и $g_{\mathrm{v}}$ и увеличивает значения $h_{\mathrm{v}}, s_{\mathrm{v}}$ и $v_{\mathrm{v}} / v_{0}$. Это связано с тем, что энергии, необходимой для изобарического создания вакансии, при учете возникновения D-атомов необходимо больше, ибо часть энергии идет на делокализацию атомов. Ни в одной из ныне существующих аналитических теорий этот факт не учитывался, что и не позволяло с помощью этих теорий корректно оценить вакансионные параметры в области плавления, где доля и роль D-атомов становится существенной $[21,22]$.

\section{5. Метод расчета коэффициента самодиффузии в кристалле}

Коэффициент диффузии $D_{f}$ равен числу атомов, переносимому через перпендикулярную выбранному направлению единичную площадку в единицу времени, при единичном в данном направлении градиенте концентрации. Таким образом, число атомов, перенесенное через площадь $S_{\mathrm{kr}}$ за время $t$ при градиенте концентрации $\operatorname{grad}($ Conc $)$, равно

$$
M_{\mathrm{tr}}=-D_{f} S_{\mathrm{kr}} t \operatorname{grad}(\text { Conc }) .
$$

Это первый закон Фика (Fick's Law) для стационарного потока $[2-4,19]$. Знак минус указывает на то, что вектор потока вещества противоположен вектору градиента скалярного поля концентрации.

Рассмотрим для простоты случай „плоской самодиффузии“ в объеме однокомпонентного кристалла, т.е. когда поток атомов направлен в одном направлении, перпендикулярном плоскости сечения. Тогда для градиента концентрации вакансий на расстоянии области доступности D-атома: $\lambda_{3}=c_{\mathrm{o}} / k_{\mathrm{p}}^{1 / 3}$, можно принять следующее выражение:

$$
\begin{aligned}
-\operatorname{grad}(\text { Conc }) & =\frac{1}{\lambda_{3}}\left[\left(\frac{1}{\lambda_{3}}\right)^{3}-\phi_{\mathrm{v}}\left(\frac{1}{\lambda_{3}}\right)^{3}\right] \\
& =\frac{1-\phi_{\mathrm{v}}}{\lambda_{3}^{4}}=\frac{\left(1-\phi_{\mathrm{v}}\right) k_{\mathrm{p}}^{4 / 3}}{c_{\mathrm{o}}^{4}} .
\end{aligned}
$$

Таким образом, выражение (24) сводится к виду

$$
M_{\mathrm{tr}}=S_{\mathrm{kr}} k_{\mathrm{p}}^{4 / 3} D_{f} \cdot \frac{\tau\left(1-\phi_{\mathrm{v}}\right)}{2 c_{\mathrm{o}}^{4}} .
$$

Для модели кристалла Эйнштейна период колебания атома в безвакансионной (ибо $\lambda_{3}$ определяется для такой системы) решетке определен формулой (16). Площадь сечения кристалла равна $S_{\mathrm{kr}}=N_{\text {cell }} S_{\text {cell }} / k_{\mathrm{p}}^{2 / 3}$, где $N_{\text {cell }}-$ число ячеек (как занятых атомами, так и вакантных), находящихся в плоскости сечения; коэффициент $k_{\mathrm{p}}^{2 / 3}$ учитывает плотность упаковки сферических атомов в плоскости сечения; $s_{\text {cell }}-$ средняя площадь одной ячейки (как занятой атомом, так и вакантной), которую, в соответствии с (1), определим следующим образом:

$$
s_{\text {cell }}=\pi\left(\frac{c}{2}\right)^{2}=\frac{\pi}{4}\left[c_{\mathrm{o}}\left(1-\phi_{\mathrm{v}}\right)^{1 / 3}\right]^{2} \cong \frac{\pi}{4} c_{\mathrm{o}}^{2} .
$$

Таким образом, из (11)-(16) получаем, что за время $t=\tau / 2$ через площадь $S_{\mathrm{kr}}$ при градиенте концентрации вакансий (25) переносится количество атомов, равное [12,17]:

$$
\begin{aligned}
M_{\mathrm{tr}} & =N_{\text {cell }} \frac{\pi c^{2}}{4} D_{f} \cdot \frac{4 \pi \hbar k_{\mathrm{p}}^{2 / 3}\left(1-\phi_{\mathrm{v}}\right)}{3 k_{\mathrm{B}} \Theta_{\mathrm{o}} c_{\mathrm{o}}^{4}} \\
& \cong N_{\text {cell }} D_{f} \cdot \frac{\pi^{2} \hbar k_{\mathrm{p}}^{2 / 3}}{3 k_{\mathrm{B}} \Theta_{\mathrm{o}} c_{\mathrm{o}}^{2}}\left(1-\phi_{\mathrm{v}}\right) .
\end{aligned}
$$

С другой стороны, из $N_{\text {cell }}$ ячеек, лежащих в плоскости сечения, только $N_{\text {cell }}\left(1-\phi_{\mathrm{v}}\right)$ заняты атомами. Из них только $N_{\text {cell }}\left(1-\phi_{\mathrm{v}}\right) x_{\mathrm{d}}$ находятся в D-состоянии. Из указанных $N_{\text {cell }}\left(1-\phi_{\mathrm{v}}\right) x_{\mathrm{d}}$ атомов только $1 / 6$ их часть будет переноситься перпендикулярно рассматриваемой площадке вдоль рассматриваемого направления. Отметим, что множитель $1 / 6$ справедлив только для равновесной самодиффузии, ибо, если имеется движущая сила, то одно из шести направлений будет иметь больший приоритет перед другими направлениями. Таким образом, за время $\tau / 2$ через выбранную площадку будет переноситься количество вещества, равное [12,17]:

$$
M_{\mathrm{tr}}=x_{\mathrm{d}} \cdot N_{\mathrm{cell}} \cdot f_{\text {cor }} \cdot \frac{\left(1-\phi_{\mathrm{v}}\right)}{6} .
$$

Здесь $f_{\text {cor }}$ - „фактор корреляции“, возникающий из-за учета ненулевой вероятности того, что ушедший в вакансию атом может сразу же вернуться обратно, не внеся вклада в диффузию $[2,3,12]$.

Сравнивая (27) и (28), легко получить выражение для коэффициента самодиффузии в объеме однокомпонентного кристалла, имеющее вид

$$
\begin{aligned}
D_{f}(\rho, T) & =D_{\mathrm{d}}(\rho) \cdot x_{\mathrm{d}}(\rho, T)=D_{\mathrm{d}}(\rho) \cdot \exp \left[-\frac{g_{\mathrm{d}}(\rho, T)}{k_{\mathrm{B}} T}\right] \\
& =D_{\mathrm{d}}(\rho) \cdot \exp \left[\frac{s_{\mathrm{d}}(\rho, T)}{k_{\mathrm{B}}}\right] \cdot \exp \left[-\frac{h_{\mathrm{d}}(\rho, T)}{k_{\mathrm{B}} T}\right] .
\end{aligned}
$$


Здесь введен предэкспоненциальный множитель следующего вида:

$$
D_{\mathrm{d}}(\rho)=f_{\text {cor }} \cdot \frac{k_{\mathrm{B}} \Theta_{\mathrm{o}} c_{\mathrm{o}}^{2}}{2 \pi^{2} \hbar k_{\mathrm{p}}^{2 / 3}} .
$$

Физический смысл множителя $D_{\mathrm{d}}(\rho)$ в том, что это такой коэффициент самодиффузии, который теоретически может быть при изохорической $(\rho=N / V=$ const $)$ делокализации всех атомов кристалла (т.е. при $\left.x_{\mathrm{d}}(\rho, T \rightarrow \infty)=1\right)$ :

$$
D_{\mathrm{d}}(\rho)=\lim _{\substack{T \rightarrow \infty \\ \rho=\text { const }}} \frac{D_{f}(\rho, T)}{x_{\mathrm{d}}(\rho, T)}=\lim _{\substack{T \rightarrow \infty \\ \rho=\text { const }}} D_{f}(\rho, T) .
$$

Отметим, что в экспериментах зависимость коэффициента самодиффузии от $P-T$-аргументов обычно описывают экспоненциальной зависимостью Аррениуса, которая имеет вид $[2,3,5]$ :

$$
D_{f}(P, T)=D_{\mathrm{o}}(P) \exp \left[-\frac{h_{\mathrm{d}}(P)}{k_{\mathrm{B}} T}\right] .
$$

При этом предполагается, что величины $D_{\text {o }}$ и $h_{\mathrm{d}}$ от температуры не зависят.

Выражения (15)-(19) и (29), (30) позволяют рассчитать зависимость коэффициента самодиффузии от плотности и температуры $D_{f}(\rho, T)$ для кристалла одноатомного вещества, исходя из его структуры $\left(k_{n}^{\mathrm{o}}\right)$, массы атома $m$ и температуры Дебая $\Theta$. Как было показано, данный метод позволяет хорошо описать функцию $D_{f}(\rho, T)$, как при температурах плавления $[12,17]$, так и при $T=0 \mathrm{~K}[12,23]$.

\section{6. Расчеты уравнения состояния и свойств кристалла золота}

В формулы (10)-(23) и (29), (30) входят следующие функции: $\Theta_{\mathrm{o}}$ - температура Дебая для безвакансионного кристалла, $\gamma_{\mathrm{o}}=-\left[\partial \ln \left(\Theta_{\mathrm{o}}\right) / \partial \ln (V)\right]_{T}-$ первый параметр Грюнайзена, $\alpha_{P}=(1 / V)(\partial V / \partial T)_{P}-$ изобарический коэффициент теплового расширения, $B_{T}=-V(\partial P / \partial V)_{T}-$ изотермический модуль упругости. Ранее, в $[11,12,17]$ при расчете активационных параметров для данных функций были использованы экспериментальные зависимости от температуры, полученные при $P=0$. Это позволило получить температурные зависимости активационных параметров при $P=0$. Но такой метод ограничивал $P-T$-диапазон расчета активационных параметров.

В дальнейшем мы использовали выражения для функций $\Theta_{о}$ и $\gamma_{0}$, полученные исходя из парного потенциала межатомного взаимодействия Ми-Леннард-Джонса, который имеет вид [18]:

$$
\varphi(r)=\frac{D}{(b-a)}\left[a\left(\frac{r_{\mathrm{o}}}{r}\right)^{b}-b\left(\frac{r_{\mathrm{o}}}{r}\right)^{a}\right],
$$

где $D$ и $r_{\mathrm{o}}-$ глубина и координата минимума потенциала, $b>a>1$ - параметры.
Тогда, как было показано в [12,24], в рамках приближения „взаимодействия только ближайших соседей“ температуру Дебая можно определить в виде

$$
\begin{aligned}
\Theta_{\mathrm{o}}\left(k_{n}^{\mathrm{o}}, c_{\mathrm{o}}\right) & =A_{w}\left(k_{n}, c_{\mathrm{o}}\right) \xi \\
& \times\left[-1+\left(1+\frac{8 D}{k_{\mathrm{B}} A_{w}\left(k_{n}^{\mathrm{o}}, c_{\mathrm{o}}\right) \xi^{2}}\right)^{1 / 2}\right],
\end{aligned}
$$

где функция $A_{w}\left(k_{n}^{\mathrm{o}}, c_{\mathrm{o}}\right)$ возникает в связи с учетом энергии „нулевых колебаний“ атомов в кристалле

$$
\begin{gathered}
A_{w}\left(k_{n}^{\mathrm{o}}, c_{\mathrm{o}}\right)=K_{R} \cdot \frac{5 k_{n}^{\mathrm{o}} a b(b+1)}{144(b-a)}\left(\frac{r_{\mathrm{o}}}{c_{\mathrm{o}}}\right)^{b+2}, \\
K_{R}=\frac{\hbar^{2}}{k_{\mathrm{B}} r_{\mathrm{o}}^{2} m}, \quad \xi=\frac{9}{k_{n}^{\mathrm{o}}} .
\end{gathered}
$$

Из (34) можно найти выражения для первого $\left(\gamma_{0}\right)$, второго $\left(q_{\mathrm{o}}\right)$ и третьего $\left(z_{\mathrm{o}}\right)$ параметров Грюнайзена. Они имеют следующий вид:

$$
\begin{gathered}
\gamma_{\mathrm{o}}=-\left(\frac{\partial \ln \Theta_{\mathrm{o}}}{\partial \ln V}\right)_{T}=\frac{b+2}{6\left(1+X_{w}\right)}, \\
q_{\mathrm{o}}=\left(\frac{\partial \ln \gamma_{\mathrm{o}}}{\partial \ln V}\right)_{T}=\gamma_{\mathrm{o}} \cdot \frac{X_{w}\left(1+2 X_{w}\right)}{\left(1+2 X_{w}\right)}, \\
z_{\mathrm{o}}=-\left(\frac{\partial \ln q_{\mathrm{o}}}{\partial \ln V}\right)_{T}=\gamma_{\mathrm{o}}\left(1+4 X_{w}\right)-2 q_{\mathrm{o}} \\
=\gamma_{\mathrm{o}} \cdot\left(\frac{1+3 X_{w}}{1+X_{w}}\right)=\frac{(b+2)\left(1+3 X_{w}\right)}{6\left(1+X_{w}\right)^{2}},
\end{gathered}
$$

где введена функция $X_{w}=A_{w} \xi / \Theta_{o}$, которая определяет роль квантовых эффектов.

Используя выражения (33)-(35), нам удалось в работах $[20,25]$ изучить изменение энергетических характеристик активационных параметров при изотермическом сжатии объема кристалла: $V / V_{0}=\left(c_{\mathrm{o}} / r_{\mathrm{o}}\right)^{3}$, вплоть до $V / V_{0} \cong 0$. Здесь, в соответствии с (2) и (33): $V=N\left[\pi /\left(6 k_{\mathrm{p}}\right)\right] c_{\mathrm{o}}^{3}$ - объем кристалла при $P-T$-аргументах, $V_{0}=N\left[\pi /\left(6 k_{\mathrm{p}}\right)\right] r_{\mathrm{o}}^{3}-$ объем кристалла при $P=0$ и $T=0 \mathrm{~K}$

Но для изучения зависимости всех активационных параметров от $P-T$-аргументов необходимо было иметь дополнительный метод, позволяющий рассчитывать как уравнение состояния $P(T, V)$, так и функции $\alpha_{P}(T, P)$ и $B_{T}(T, P)$, исходя из параметров межатомного потенциала (33). Кроме этого, было необходимо в рамках данного метода расчета самосогласованно определить все четыре параметра межатомного потенциала (33). Эти задачи были решены в [26-28], где был разработан аналитический метод расчета свойств однокомпонентного кристалла, который не содержит вакансий и делокализованных атомов. Именно на основе этого метода в [28] были определены параметры межатомного потенциала для 15 однокомпонентных металлов. 


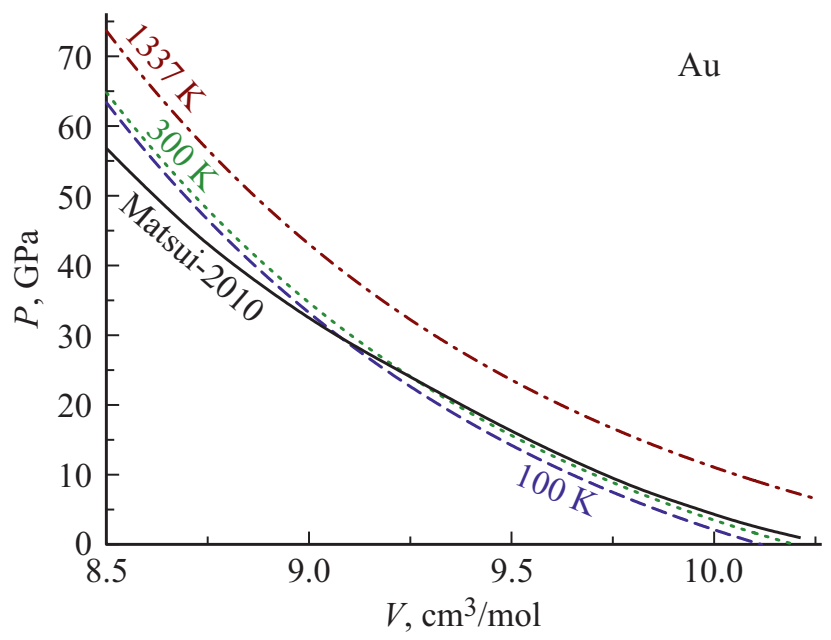

Рис. 1. Изотермы уравнения состояния золота. Сплошная кривая - экспериментальная зависимость для $T=300 \mathrm{~K}$ из [29]. Другие кривые - это результаты наших расчетов: нижняя штриховая кривая - для $T=100 \mathrm{~K}$, средняя точечная кривая — при $T=300 \mathrm{~K}$, верхняя штрих-пунктирная кривая при $T=1337 \mathrm{~K}$.

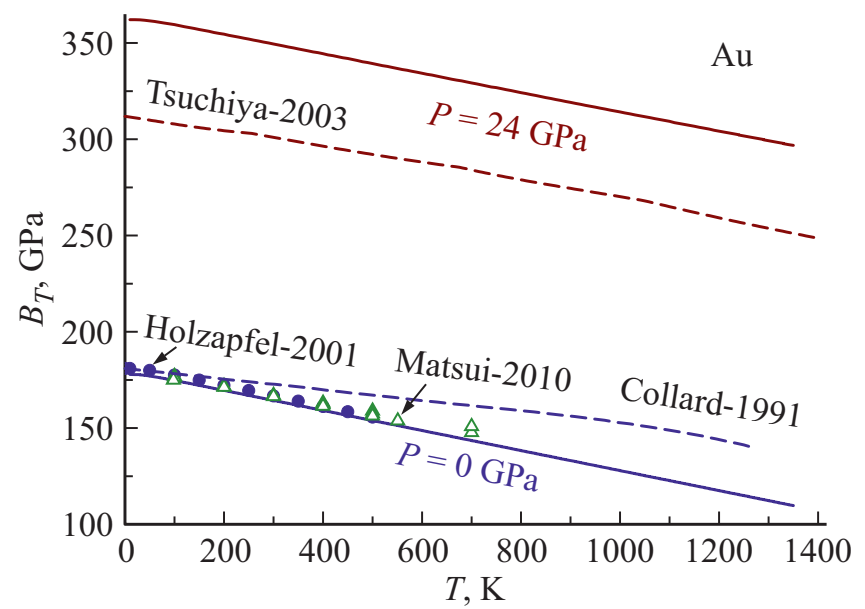

Рис. 2. Изобарные зависимости изотермического модуля упругости золота от температуры. Нижняя и верхняя сплошные линии - наши расчеты, полученные при $P=0$ и $24 \mathrm{GPa}$ соответственно. Символы - экспериментальные данные при $P=0$ : сплошные кружки - данные из [30], открытые треугольники - данные из [29]. Нижняя штриховая линия экспериментальная зависимость из [31], верхняя штриховая линия - теоретическая зависимость, полученная при $P=24 \mathrm{GPa}$ в [32].

В данной работе с помощью метода из [26-28] мы рассчитали свойства золота $(\mathrm{Au}, m(\mathrm{Au})=196.967$ a.m.u., $\left.T_{\mathrm{m}}(P=0)=1337.58 \mathrm{~K}\right)$, которое имеет гранецентрированную кубическую (ГЦК) структуру $\left(k_{n}^{\mathrm{o}}=12\right.$, $\left.k_{\mathrm{p}}=0.7405\right)$. Золото - это мало окисляемый, инертный и пластичный металл, который не испытывает полиморфных фазовых переходов. Для ГЦК-Аи параметры парного межатомного потенциала (33) были определены в [28], и они имеют следующие значения:

$$
\begin{gathered}
r_{\mathrm{o}}=2.8700 \cdot 10^{-10} \mathrm{~m}, \quad D / k_{\mathrm{B}}=7446.04 \mathrm{~K}, \\
b=15.75, \quad a=2.79 .
\end{gathered}
$$

На рис. 1 представлены изотермические зависимости уравнения состояния от объема $P(T, V)$ для золота.

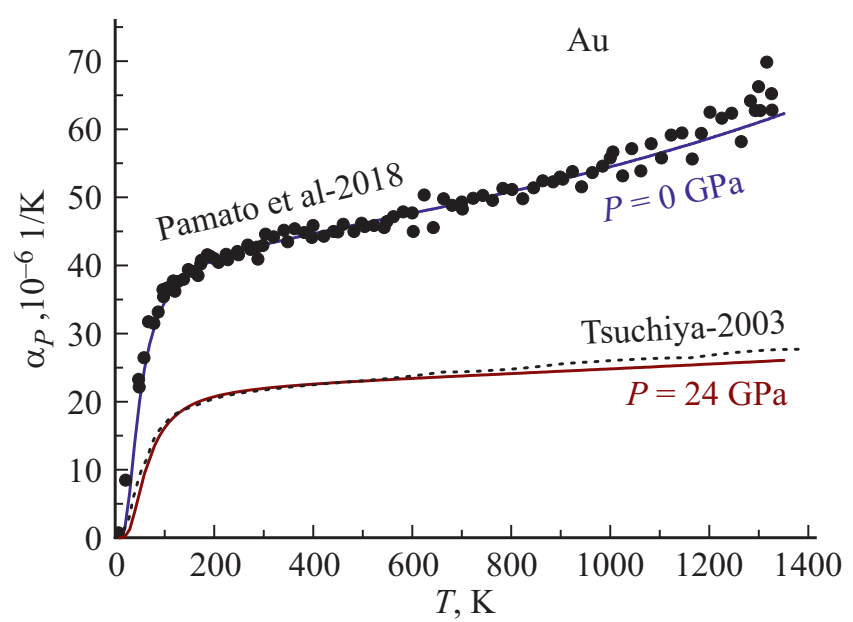

Рис. 3. Изобарные зависимости коэффициента теплового объемного расширения золота от температуры. Верхняя и нижняя сплошные линии - наши расчеты, полученные при $P=0$ и $24 \mathrm{GPa}$ соответственно. Сплошные кружки - экспериментальные данные при $P=0$ из [33]. Штриховая линия, которая сливается с нижней сплошной линией - теоретическая зависимость, полученная при $P=24 \mathrm{GPa}$ в [32].

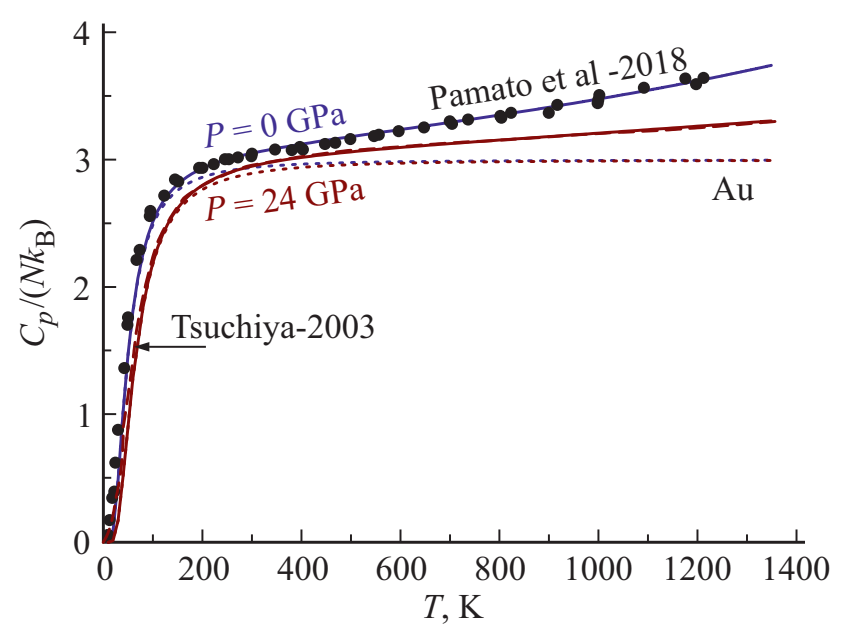

Рис. 4. Изобарные зависимости нормированной изобарной теплоемкости золота от температуры. Верхняя и нижняя сплошные линии - наши расчеты, полученные при $P=0$ и $24 \mathrm{GPa}$ соответственно. Сплошные кружки - экспериментальные данные при $P=0$ из [33]. Штриховая линия, которая сливается с нижней сплошной линией - теоретическая зависимость, полученная при $P=24 \mathrm{GPa}$ в [32]. Тонкими точечными линиями показаны наши расчетные зависимости для $C_{\mathrm{v}} /\left(N k_{\mathrm{B}}\right)-$ нормированной изохорной теплоемкости при $P=0$ и $24 \mathrm{GPa}$ соответственно, которые, в соответствии с законом Дюлонга-Пти, сливаются при высоких температурах в линию $C_{\mathrm{v}} /\left(N k_{\mathrm{B}}\right)=3$. 
На рис. 2-4 представлены изобарные зависимости от температуры различных свойств ГЦК-Аu: на рис. 2 представлена зависимость для модуля упругости $B_{T}(P, T)$, на рис. 3 - для коэффициента теплового расширения $\alpha_{P}(P, T)$, на рис. 4 - для изобарной теплоемкости: $C_{p}(P, T)=C_{v}\left(1+\gamma \alpha_{P} T\right)$, где $C_{v}-$ это изохорная теплоемкость.

Как видно из рис. 1-4, предложенный метод позволяет получить корректные изобарные температурные зависимости свойств золота как при $P=0$, так и при $24 \mathrm{GPa}$. Представленное на рис. $1-4$ хорошее согласие с экспериментальными зависимостями для золота при $P=0$ указывает на очень малый вклад вакансий и делокализации атомов в температурные зависимости указанных свойств при $P=0$. Как было показано в [20,25], при изотермическом росте давления вклад активационных процессов в решеточные свойства кристалла уменьшается еще сильнее. Вместе с тем, как было показано в $[21,22]$, именно активационные процессы ответственны за такие эффекты как сублимация и плавление кристалла, особенно при высоких давлениях.

\section{7. Температурная и барическая зависимость активационных параметров}

Расчет температурной зависимости активационных параметров для золота проведен от $10 \mathrm{~K}$ до $1330 \mathrm{~K}$ вдоль двух изобар: $P=0$ и $24 \mathrm{GPa}$. На рис. 5 кривыми $1-6$ показаны рассчитанные нами изобарные зависимости от обратной температуры для активационных параметров золота. Кривые 1 и 2 - это логарифм вероятности образования вакансии (10), кривые 3 и 4 - это логарифм делокализации атома (15), кривые 5 и 6 - это логарифм коэффициента самодиффузии (29). Сплошные кривые $1,3,5$ - это изобары $P=0$, штриховые кривые 2, 4, 6 - это изобары $P=24 \mathrm{GPa}$. Штрих-пунктирная прямая 7 указывает две экспериментальные зависимости для логарифма коэффициента самодиффузии, полученные при $P=0$ по уравнению Аррениуса (32) на интервале температур от 600 до $1320 \mathrm{~K}$ в работах $[34,35]$ со следующими параметрами:

$$
\begin{aligned}
& D_{\mathrm{o}}=0.091 \pm 0.001 \mathrm{~cm}^{2} / \mathrm{s}, \quad h_{d}=1.81 \pm 0.01 \mathrm{eV}, \quad[34], \\
& D_{\mathrm{o}}=0.107 \pm 0.002 \mathrm{~cm}^{2} / \mathrm{s}, \quad h_{d}=1.834 \pm 0.002 \mathrm{eV}[35] .
\end{aligned}
$$

В масштабе рис. 5 данные зависимости сливаются в линию 7.

Из рис. 5 видно, что при высоких температурах наша зависимость 5 для функции $\lg \left(D_{f} /\left[\mathrm{cm}^{2} / \mathrm{s}\right]\right)$ проходит несколько круче, чем экспериментальная прямая 7. Это обусловлено тем, что наша зависимость 5 рассчитана для идеального кристалла, а зависимость 7 измерена для реального кристалла, содержащего как дислокации, так и границы зерен, которые существенно увеличивают коэффициент самодиффузии при высоких температурах.

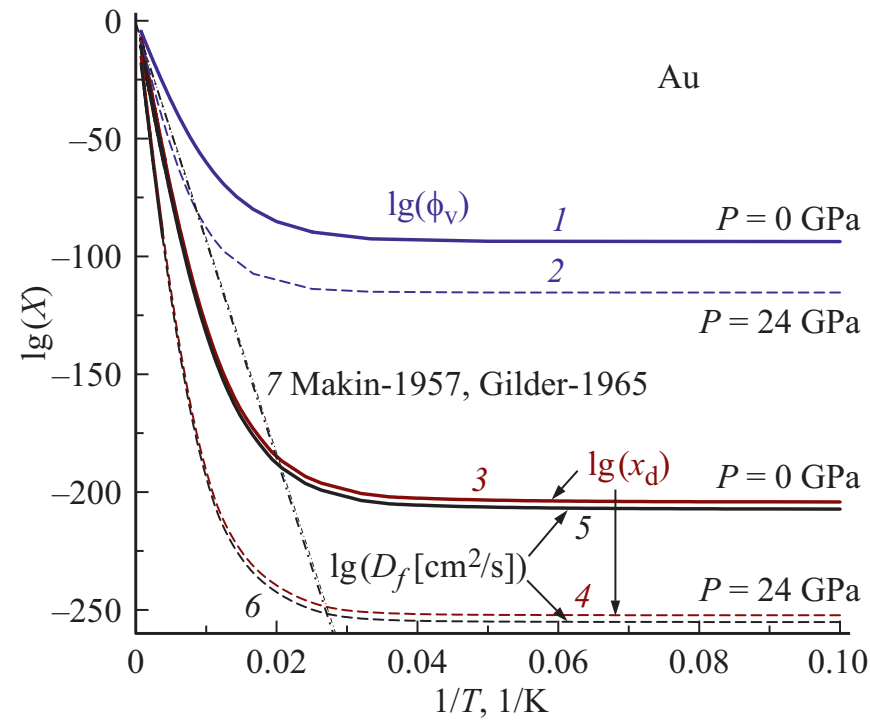

Рис. 5. Изобарные зависимости от обратной температуры для активационных параметров золота. Кривые 1 и 2 - расчет логарифма вероятности образования вакансии (10), кривые 3 и 4 - расчет логарифма делокализации атома (15), кривые 5 и 6 - расчет логарифма коэффициента самодиффузии (29). Сплошные кривые $1,3,5$ - изобары $P=0$, штриховые кривые 2,4,6 - изобары $P=24 \mathrm{GPa}$. Штрих-пунктирная прямая 7 - экспериментальные зависимости для логарифма коэффициента самодиффузии, полученные при $P=0$ в $[34,35]$.

Именно поэтому в работах [36,37] было предложено представлять экспериментальный коэффициент самодиффузии в виде двух слагаемых:

$$
D_{f}=D_{\text {perf }}+D_{\text {def }},
$$

где $D_{\text {perf }}$ - это коэффициент самодиффузии в решетке „совершенного“ кристалла, $D_{\text {def }}-$ коэффициент самодиффузии по дефектным местам: по дислокациям, по границам зерен и т. д.

На рис. 6-9 показаны температурные зависимости для термодинамических параметров активационных процессов, рассчитанные по формулам (20)-(23): энергии Гиббса $\left(g_{i}\right)$, энтальпии $\left(h_{i}=g_{i}+T s_{i}\right)$, энтропии $\left(s_{i}\right)$ и объема $\left(v_{i}\right)$ активационного процесса. Расчеты проведены при $P=0$ (сплошные кривые $1,3,5$ ) и при $P=24 \mathrm{GPa}$ (штриховые кривые $2,4,6$ ).

Наряду с параметрами самодиффузии $(i=\mathrm{d}$, кривые 3 и 4$)$ и процесса образования вакансии $(i=\mathrm{v}$, кривые 1 и 2) были также рассчитаны термодинамические параметры миграции $(i=\mathrm{m}$, кривые 5 и 6$)$. Они определялись как разность между параметрами самодиффузии и соответствующими параметрами для образования вакансии $[1,4]$ :

$$
\begin{aligned}
& g_{\mathrm{m}}=g_{\mathrm{d}}-g_{\mathrm{v}}, \quad h_{\mathrm{m}}=h_{\mathrm{d}}-h_{\mathrm{v}}, \\
& s_{\mathrm{m}}=s_{\mathrm{d}}-s_{\mathrm{v}}, \quad v_{\mathrm{m}}=v_{\mathrm{d}}-v_{\mathrm{v}} .
\end{aligned}
$$



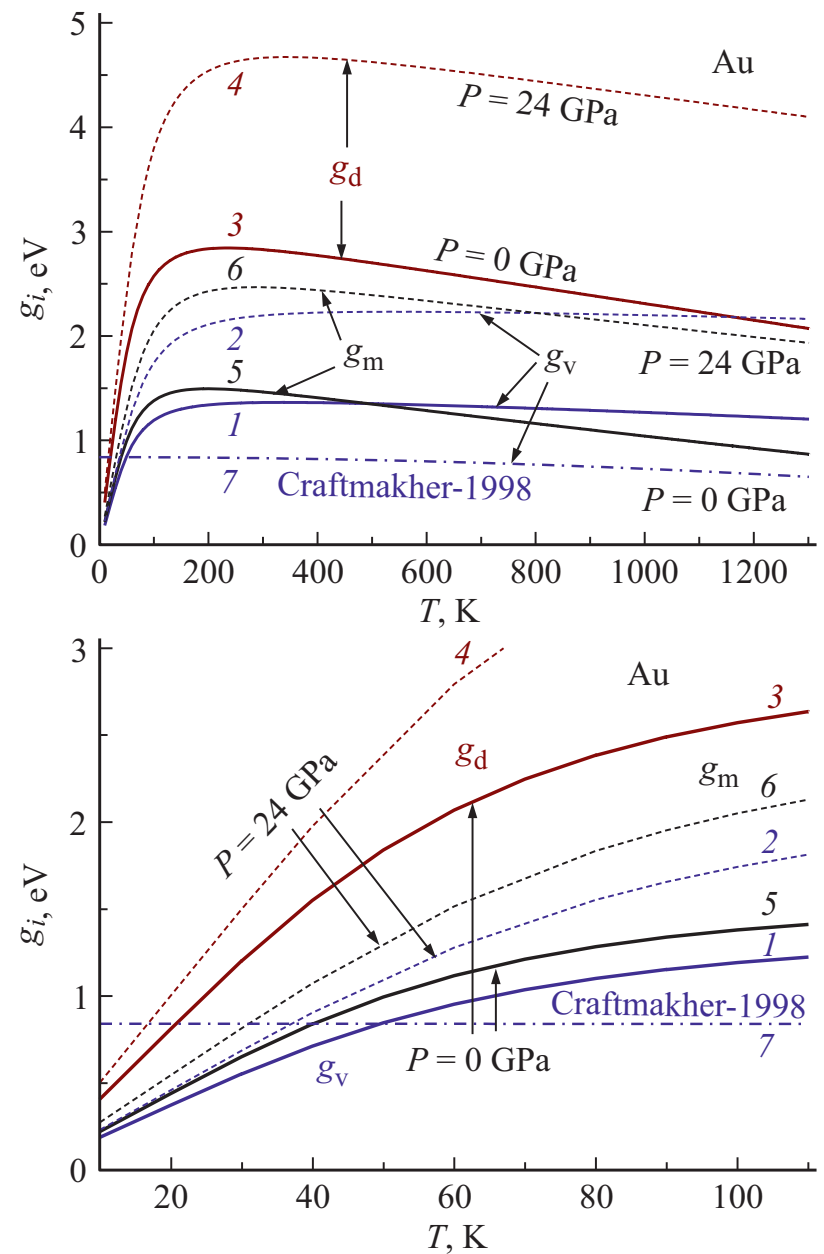

Рис. 6. Температурные зависимости энергии Гиббса активационного процесса для золота. Кривые 1 и $2-$ расчет энергии Гиббса для образования вакансии (21), кривые 3 и $4-$ расчет энергии Гиббса для делокализации атома (22), кривые 5 и $6-$ расчет энергии Гиббса для миграции атома (39). Сплошные кривые $1,3,5-$ изобары $P=0$, штриховые кривые $2,4,6-$ изобары $P=24 \mathrm{GPa}$. Штрих-пунктирная прямая $7-$ это зависимость $(40)$ из $[1$, р. 164]. На верхнем графике показаны зависимости $g_{i}(T)$ для всей области температур, на нижнем графике - для области низких температур $(i=\mathrm{v}, \mathrm{d}, \mathrm{m})$.

Штрих-пунктирные прямые 7 на рис. 6 и 7 - это температурные зависимости энергии Гиббса $g_{\mathrm{v}}$ и энтальпии $h_{\mathrm{v}}$ для процесса образования вакансии вида

$$
\begin{aligned}
& g_{\mathrm{v}}, \mathrm{eV}=0.84-0.2\left(\frac{T}{T_{\mathrm{m}}}\right)^{2}, \\
& h_{\mathrm{v}}, \mathrm{eV}=0.84+0.2\left(\frac{T}{T_{\mathrm{m}}}\right)^{2} .
\end{aligned}
$$

Зависимости (40) были построены в [1, p. 164], по экспериментальным данным для $h_{\mathrm{v}}$, полученного при $P=0$, на интервале температур от 600 до $1320 \mathrm{~K}$.

Из рис. 6 видно, что $g_{i}(P, T=0 \mathrm{~K})=0$, причем все изобарные зависимости $g_{i}(T)$ имеют максимумы, положение которых с ростом давления смещаются в сторону больших температур. На всем температурном интервале выполняются неравенства

$$
g_{\mathrm{d}}(P, T)>g_{\mathrm{m}}(P, T) \quad \text { и } \quad g_{\mathrm{d}}(P, T)>g_{\mathrm{v}}(P, T) .
$$

Но зависимости $g_{\mathrm{m}}(P, T)$ и $g_{\mathrm{v}}(P, T)$ имеют точку пересечения, положение которой с ростом давления смещается в сторону больших температур. В области высоких температур все три функции $g_{i}(T)$ линейно уменьшаются с ростом температуры. При изотермическом росте давления все три энергии Гиббса активационного процесса возрастают на всем температурном интервале.

Из рис. 7 видно, что все изобарные зависимости $h_{i}(T)$ монотонно возрастают, причем $h_{i}(P, T=0 \mathrm{~K})=0$. На
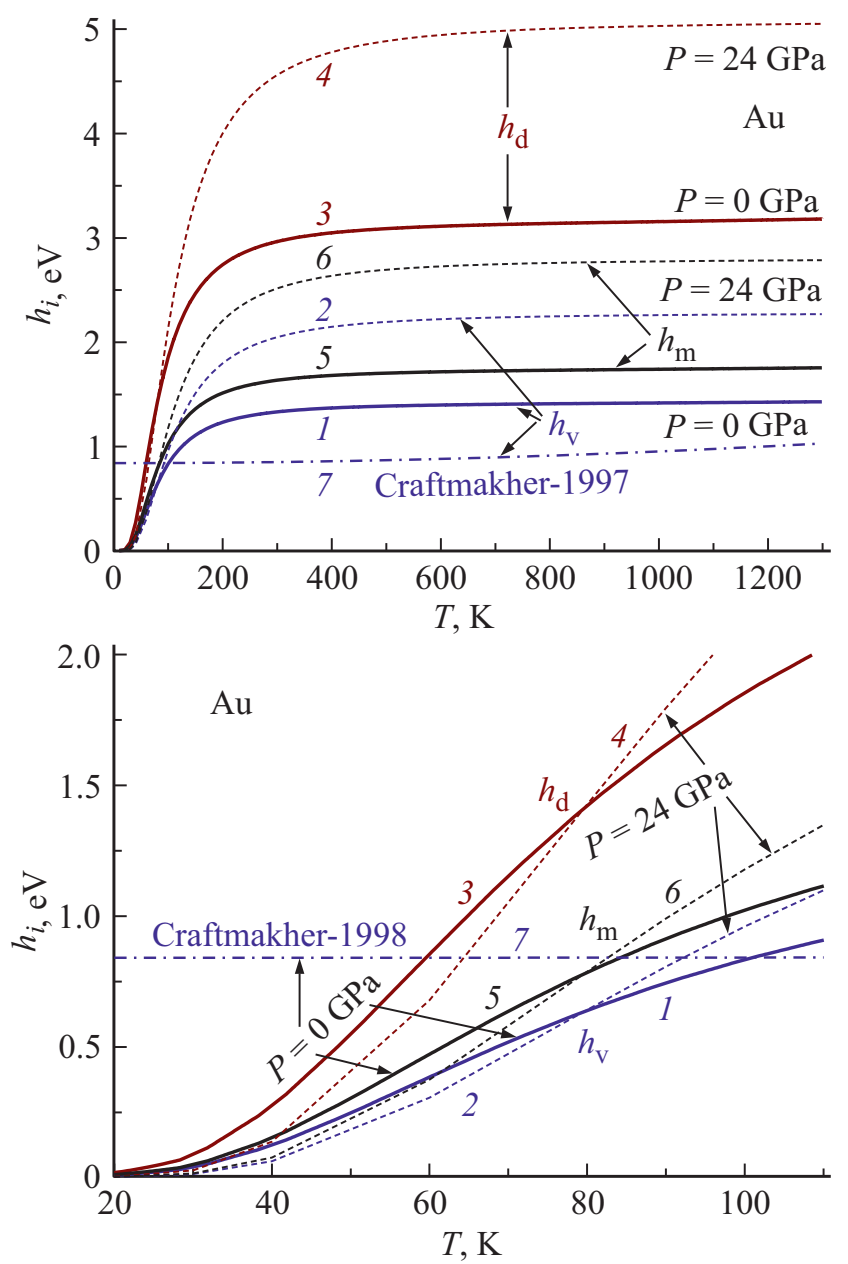

Рис. 7. Температурные зависимости энтальпии активационного процесса для золота. Кривые 1 и $2-$ расчет энтальпии образования вакансии (21), кривые 3 и 4 - расчет энтальпии делокализации атома (22), кривые 5 и 6 - расчет энтальпии миграции атома (39). Сплошные кривые $1,3,5-$ изобары $P=0$, штриховые кривые $2,4,6-$ изобары $P=24 \mathrm{GPa}$. Штрихпунктирная прямая 7 - это зависимость (40) из [1, р. 164]. На верхнем графике показаны зависимости $h_{i}(T)$ для всей области температур, на нижнем графике - для области низких температур $(i=\mathrm{v}, \mathrm{d}, \mathrm{m})$. 
всем температурном интервале выполняются следующие неравенства:

$$
h_{\mathrm{d}}(P, T)>h_{\mathrm{m}}(P, T)>h_{\mathrm{v}}(P, T) .
$$

При изотермическом росте давления энтальпия активационного процесса возрастает при высоких температурах, что физически понятно. Но, как видно из нижнего графика рис. 7, ниже определенной температуры (индивидуальной для процесса образования вакансий и самодиффузии), при изотермическом сжатии энтальпия активационного процесса уменьшается. Это обусловлено температурно-барической зависимостью энтропии активационного процесса в функции: $h_{i}=g_{i}+T s_{i}$.

Энтальпия активационного процесса - это единственный измеримый параметр из 4-х, которые характеризуют активационный процесс. Однако эксперимен-
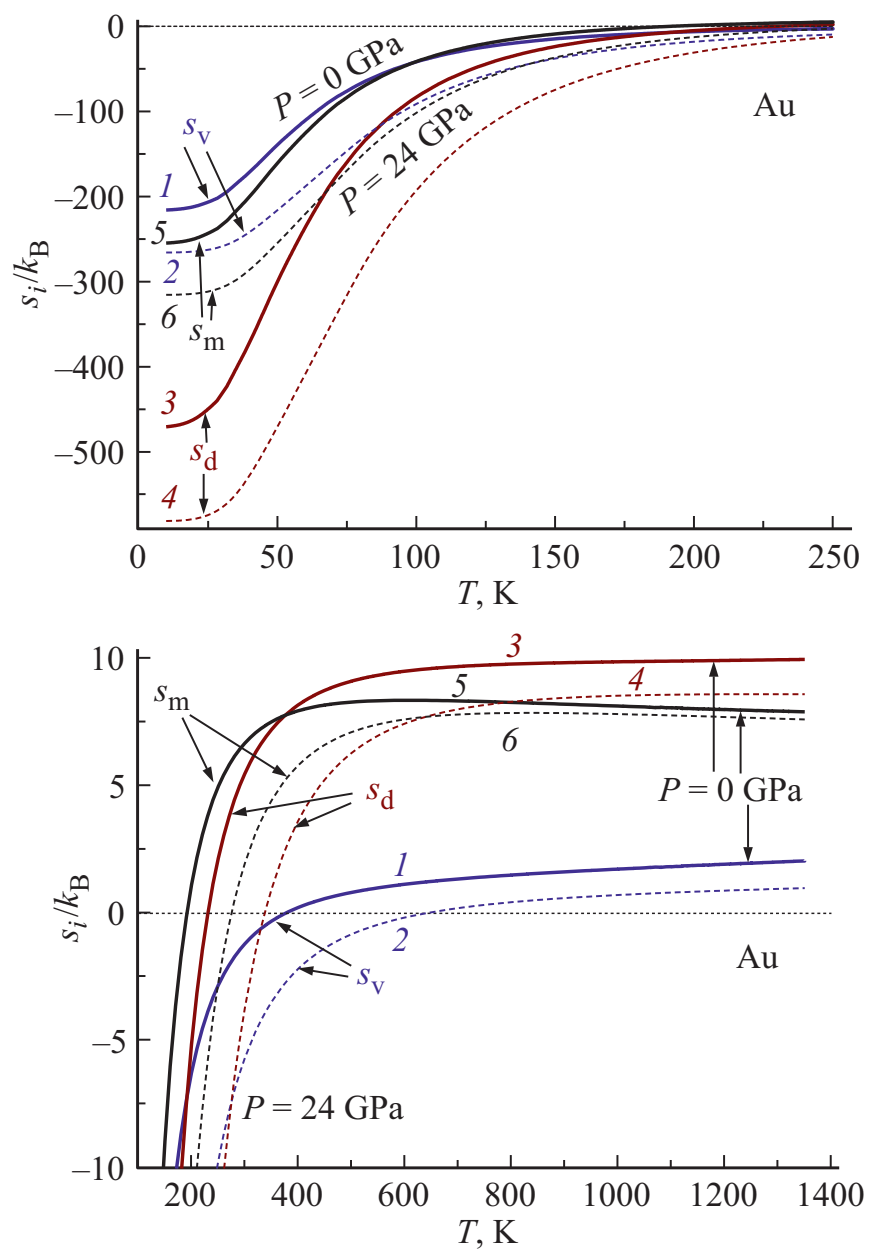

Рис. 8. Температурные зависимости энтропии активационного процесса, рассчитанные для золота. Кривые 1 и 2 - для энтропии образования вакансии из (21), кривые 3 и 4 для энтропии делокализации атома из (22), кривые 5 и 6 для энтропии миграции атома из (39). Сплошные кривые $1,3,5$ - изобары $P=0$, штриховые кривые $2,4,6$ - изобары $P=24 \mathrm{GPa}$. На верхнем графике показаны зависимости $s_{i}(T)<0$ в области низких температур, на нижнем графике для области высоких температур $(i=\mathrm{v}, \mathrm{d}, \mathrm{m})$. тальное определение $h_{i}$ было проведено только при высоких температурах $(T \gg \Theta)$, где активационные процессы оказывают максимальное влияние на свойства кристалла и потому величину $h_{i}$ можно экспериментально оценить. При этом используется экспоненциальная зависимость Аррениуса типа (32) и предполагается, что энтальпия активационного процесса от температуры не зависит.

Энтальпии образования вакансии и самодиффузии для золота были измерены при $P=0$ на интервале температур от 600 до $1320 \mathrm{~K}$ разными методами. Они лежат в интервале

$$
\begin{aligned}
& h_{\mathrm{v}}(T \gg \Theta)=0.89-1.02 \mathrm{eV}[1], \\
& h_{\mathrm{d}}(T \gg \Theta)=1.71-1.833 \mathrm{eV}[5] .
\end{aligned}
$$

Наши данные на указанном интервале температур превышают экспериментальные оценки. Это может быть обусловлено как отличием нашей модели бездефектного кристалла от реального кристалла, так и приближенностью наших расчетов, основанных только на 4-х параметрах (37) для парного потенциала межатомного взаимодействия (33).

Вместе с тем, современные методы компьютерного моделирования (first-principles density functional theory DFT, embedded-atom method - EAM, и другие) позволили рассчитать энтальпию образования вакансии только при $T=0 \mathrm{~K}$ и при неопределенном давлении. Такими методами для золота были получены следующие значения [38]:

$$
\begin{aligned}
& h_{\mathrm{v}}(T=0 \mathrm{~K}), \mathrm{eV}=0.42-0.67 \text { (DFT-PBE } \\
& \\
&(\text { Perdew, Burke, Ernzerhof }))- \\
& 0.62-0.72(\mathrm{DFT}-\mathrm{LDA} \\
&(\text { local density approximation }))- \\
& 0.71(\text { EAM and LSGF } \\
&(\text { locally self-consistent Green's-function }))- \\
& 0.72(\text { DFT-HSE } \\
&(\text { Heyd, Scuseria, Ernzerhof }))- \\
& 0.82(\text { FP-LMTO } \\
&(\text { full potential linear muffin-tin orbital }))- \\
&1.24(\text { TB (tight-binding method })) .
\end{aligned}
$$

В работе [39] вышеуказанные DFT-методы компьютерного моделирования были дополнены процедурой коррекции (Posteriori surface error correction), которая позволила приблизить результаты DFT-методов к экспериментальной величине $h_{\mathrm{v}}(T \gg \Theta)$ из (42):

$h_{\mathrm{v}}(T=0 \mathrm{~K}), \mathrm{eV}=0.84($ DFT-LDA $)-0.87$ (DFT-PBE) 0.92 (DFT-revTPSS (Tao, Perdew, Staroverov, Scuseria)) 1.01 (DFT-PW91 (Perdew, Wang)).

Из рис. 8 видно, что все изобарные зависимости $s_{i}(T)$ при низких температурах лежат в отрицательной 


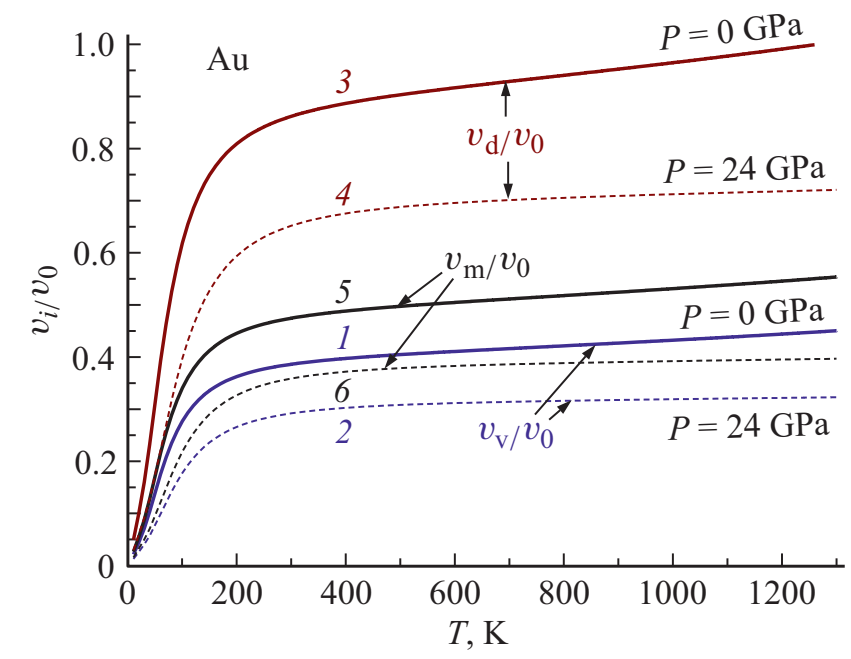

Рис. 9. Температурные зависимости объема активационного процесса, нормированного на объем атома, рассчитанные для золота. Кривые 1 и $2-$ расчет объема образования вакансии по (21), кривые 3 и 4 - расчет объема делокализации атома по (22), кривые 5 и 6 - расчет объема миграции атома по (39). Сплошные кривые $1,3,5-$ изобары $P=0$, штриховые кривые 2, 4, 6 - изобары $P=24 \mathrm{GPa}(i=\mathrm{v}, \mathrm{d}, \mathrm{m})$.

области, причем выполняются соотношения

$$
s_{\mathrm{d}}(P, T=0 \mathrm{~K})<s_{\mathrm{m}}(P, T=0 \mathrm{~K})<s_{\mathrm{v}}(P, T=0 \mathrm{~K})<0 .
$$

Но в области высоких температур эти соотношения изменяются к следующему виду:

$$
s_{\mathrm{d}}(P, T \gg \Theta)>s_{\mathrm{m}}(P, T \gg \Theta)>s_{\mathrm{v}}(P, T \gg \Theta)>0 .
$$

При изотермическом росте давления энтропия активационного процесса уменьшается на всем температурном интервале.

Отметим, что до сих пор не разработано экспериментальных либо теоретических методов для корректной оценки не только температурной зависимости $s_{i}(T)$, но даже величины энтропии активационного процесса при $P=0$ и $T \gg \Theta[8,9,33,40]$. В связи с этим в литературе встречаются различные косвенные оценки для $s_{i}(T \gg \Theta)$, которые все положительные, но существенно различаются. Например, для золота используются следующие значения энтропии образования вакансии:

$$
\begin{gathered}
s_{\mathrm{v}}(T \gg \Theta) / k_{\mathrm{B}}=3.15[1, \text { p. 164], } 0.5[19], \\
1.03-1.26[33], \quad 0.5-3.1[41], \quad 0.5-0.7[42] .
\end{gathered}
$$

Найти в литературе каких-либо экспериментальных либо теоретических оценок величины $s_{\mathrm{d}}(T \gg \Theta)$ для золота нам пока не удалось.

Из рис. 9 видно, что все изобарные зависимости $v_{i}(T)$ монотонно возрастают с ростом температуры, причем $v_{i}(P, T=0 \mathrm{~K})=0$. При расчетах мы брали $v_{0}=\pi \cdot r_{\mathrm{o}}^{3} /\left(6 k_{\mathrm{p}}\right)$ - это объем атома в совершенном кристалле при $P=0$ и $T=0 \mathrm{~K}$. Из рис. 9 видно, что на всем температурном интервале выполняется следующее соотношение:

$$
v_{\mathrm{d}}(P, T)>v_{\mathrm{m}}(P, T)>v_{\mathrm{v}}(P, T)>0 .
$$

Экспериментальное определение объема активационного процесса - это очень трудоемкий процесс, а теоретические оценки для $v_{i}$ очень приближенные $[43,44]$. В литературе представлены следующие оценки для нормированного значения активационного объема золота (в скобках указаны теоретические оценки):

$$
\begin{gathered}
v_{\mathrm{v}}(T \gg \Theta) / v_{0}=(0.63-0.73), \quad 0.52[1, \text { p. 92]; } \\
0.50-0.59[7] ; \quad 0.52-0.65[33,44] ; \\
(0.35-0.48), \quad 0.45-0.59[42] ; 0.45-0.57[43] ; \\
0.3-0.5(\text { при } T<\Theta), 0.5-0.7(\text { при } T>\Theta)[45] ; \\
(0.73), \quad 0.52-0.85[46] ; \quad(0.73), \quad 0.85[47] ; \\
v_{\mathrm{d}}(T \gg \Theta) / v_{0}=0.706[2]: 0.65-0.90[7] ; \\
0.60-0.72[43] ; \quad 0.73-0.77[48] .
\end{gathered}
$$

Из рис. 9 видно, что при изотермическом сжатии объем активационного процесса уменьшается. Уменьшение объема образования вакансии при изотермическом сжатии отмечалась также в [49] для ОЦК-Та и в [50] для ГЦК-Аu, следующим образом:

$$
\begin{gathered}
v_{\mathrm{d}}(T=953 \mathrm{~K}) / v_{0}=0.65 \text { при } P=0.6 \mathrm{GPa}, \\
0.53 \text { при } P=1.1 \mathrm{GPa} .
\end{gathered}
$$

Кроме этого, в работах $[42,51]$ для однокомпонентных металлов было получено соотношение $v_{\mathrm{v}}(T \gg \Theta) \approx 8 \Delta v_{\mathrm{m}}$, где $\Delta v_{\mathrm{m}}$ - удельный скачок объема при плавлении. Так как величина $\Delta v_{\mathrm{m}}$ уменьшается с ростом давления, то это соотношение также указывает на уменьшение величины $v_{\mathrm{v}}(T \gg \Theta)$ с ростом давления.

\section{8. Поведение активационных параметров при низких температурах}

При $T \ll \Theta-$ функции $f_{y}(T)$ и $t_{y}(T)$ из (7) и (23) сильно меняются с температурой, причем выполняются следующие предельные соотношения:

$$
\begin{aligned}
f_{y}(T=0 \mathrm{~K})=\lim _{\frac{T}{\Theta_{0}} \rightarrow 0} f_{y}\left(\frac{\Theta_{0}}{T}\right)=\frac{8}{3} \lim _{\frac{T}{\Theta_{0}} \rightarrow 0}\left(\frac{T}{\Theta_{0}}\right)=0 \\
t_{y}(T=0 \mathrm{~K})=\lim _{\frac{T}{\Theta_{0}} \rightarrow 0} t_{y}\left(\frac{\Theta_{0}}{T}\right) \\
=1-\frac{6}{4} \lim _{\frac{T}{\Theta_{0}} \rightarrow 0}\left(\frac{\Theta_{0}}{T}\right) \exp \left(-\frac{3 \Theta_{0}}{4 T}\right)=1
\end{aligned}
$$

где $\Theta_{0}=\Theta_{\mathrm{o}}(T=0 \mathrm{~K})$ - температура Дебая, рассчитанная для бездефектного кристалла при $T=0 \mathrm{~K}$. 
Учитывая, что при низких температурах выполняется: $\alpha_{P}(T) \sim T^{3}[14,18,19]$ (т.е. имеем: $\alpha_{P}(0)=0$ ), из формул (3) и (15) можно получить следующие выражения для вероятности активационных процессов при $T=0 \mathrm{~K}[12,23,52]$ :

$$
\begin{gathered}
\phi_{\mathrm{v}}(0)=\frac{N_{\mathrm{v}}(0)}{N+N_{\mathrm{v}}(0)}=\frac{2}{\pi^{1 / 2}} \int_{\left(M_{\mathrm{v}}\right)^{1 / 2}}^{\infty} \exp \left(-t^{2}\right) d t \\
\cong \frac{1}{\left(\pi M_{\mathrm{v}}\right)^{1 / 2}} \exp \left(-M_{\mathrm{v}}\right), \\
x_{\mathrm{d}}(0)=\frac{N_{\mathrm{d}}(0)}{N}=\frac{2}{\pi^{1 / 2}} \int_{M_{\mathrm{d}}}^{\infty} t^{1 / 2} \exp (-t) d t \\
\cong 2\left(\frac{M_{\mathrm{d}}}{\pi}\right)^{1 / 2} \exp \left(M_{\mathrm{d}}\right),
\end{gathered}
$$

где параметры $M_{\mathrm{v}}$ и $M_{\mathrm{d}}$ представляют следующие предельные отношения

$$
\begin{gathered}
M_{\mathrm{v}}=\lim _{\frac{T}{\Theta_{0}} \rightarrow 0}\left(\frac{E_{\mathrm{v}}}{k_{\mathrm{B}} T}\right)=\frac{M_{\mathrm{L}}}{1+x_{\mathrm{d}}(0)\left(C_{\mathrm{D}} M_{\mathrm{L}}-1\right)}, \\
M_{\mathrm{d}}=\lim _{\frac{T}{\Theta_{0}} \rightarrow 0}\left(\frac{E_{\mathrm{d}}}{k_{\mathrm{B}} T}\right)=\frac{8 E_{\mathrm{d} 1}(0)}{3 k_{\mathrm{B}} \Theta_{0}}=C_{\mathrm{LD}} M_{\mathrm{L}} .
\end{gathered}
$$

Здесь введены следующие обозначения:

$$
\begin{gathered}
M_{\mathrm{L}}=\lim _{\frac{T}{\Theta_{0}} \rightarrow 0}\left(\frac{E_{\mathrm{L}}}{k_{\mathrm{B}} T}\right)=\frac{8 E_{\mathrm{L} 1}(0)}{3 k_{\mathrm{B}} \Theta_{0}}=\frac{3 m k_{\mathrm{B}} \Theta_{0}}{8 k_{n}^{\mathrm{o}}}\left[\frac{c_{\mathrm{o}}(0)}{\hbar}\right]^{2}, \\
E_{\mathrm{L} 1}(0)=E_{\mathrm{L}}\left(T=0 \mathrm{~K}, f_{y}=1\right)=\frac{m}{k_{n}^{\mathrm{o}}}\left[\frac{3 c_{\mathrm{o}}(0) k_{\mathrm{B}} \Theta_{0}}{8 \hbar}\right]^{2}, \\
E_{\mathrm{d} 1}(0)=E_{\mathrm{d}}\left(T=0 \mathrm{~K}, f_{y}=1\right)=\frac{27 m}{128 k_{\mathrm{p}}^{2 / 3}}\left[\frac{c_{\mathrm{o}}(0) k_{\mathrm{B}} \Theta_{0}}{\pi \hbar}\right]^{2} .
\end{gathered}
$$

Таким образом, при $T=0 \mathrm{~K}$ в кристалле существуют „нулевые вакансии“, а коэффициент самодиффузии отличен от нуля: $\phi_{\mathrm{v}}(0)>0$ и $x_{\mathrm{d}}(0)>0$. Этот эффект обусловлен наличием у атомов „нулевых колебанийс и был предсказан еще Андреевым и Лифшицем в 1969 г. [53,54]. Соответственно, активационная формула Аррениуса с не зависящей от температуры энергией активации при низких температурах уже неприменима для описания активационных процессов.

Для термодинамических параметров активационных процессов при $T=0 \mathrm{~K}$ получим следующие предельные соотношения [12,23,52]:

для процесса образования вакансии

$$
\begin{gathered}
\lim _{\frac{T}{\Theta_{0}} \rightarrow 0}\left(\frac{g_{\mathrm{v}}}{k_{\mathrm{B}} T}\right)=M_{\mathrm{v}}+0.5 \ln \left(\pi M_{\mathrm{v}}\right), \quad \lim _{\frac{T}{\Theta_{0}} \rightarrow 0}\left(\frac{h_{\mathrm{v}}}{k_{\mathrm{B}} T}\right)=0, \\
\lim _{\frac{T}{\Theta_{0}} \rightarrow 0}\left(\frac{s_{\mathrm{V}}}{k_{\mathrm{B}}}\right)=\frac{s_{\mathrm{v}}(0)}{k_{\mathrm{B}}}=-M_{\mathrm{v}}-0.5 \ln \left(\pi M_{\mathrm{v}}\right),
\end{gathered}
$$

$$
\begin{gathered}
\lim _{\frac{T}{\Theta_{0}} \rightarrow 0}\left(\frac{v_{\mathrm{v}}}{v_{\mathrm{a}}}\right)=\frac{v_{\mathrm{v}}(0)}{v_{\mathrm{a}}(0)}=0 \\
\lim _{\frac{T}{\Theta_{0}} \rightarrow 0}\left(\frac{v_{\mathrm{v}} B_{T}}{k_{\mathrm{B}} T}\right)=\phi_{E 0}\left[\gamma_{\mathrm{o}}(0)-\frac{2}{3}\right] \\
=M_{\mathrm{v}}\left[1+x_{\mathrm{d}}(0) C_{\mathrm{D}} M_{\mathrm{v}} M_{\mathrm{d}} G_{\mathrm{d} 0}\right] \cdot\left[\gamma_{\mathrm{o}}(0)-\frac{2}{3}\right], \\
\phi_{E 0}=M_{\mathrm{v}}\left[1+x_{\mathrm{d}} C_{\mathrm{D}} M_{\mathrm{v}} M_{\mathrm{d}} G_{\mathrm{d} 0}\right] \\
G_{\mathrm{d} 0}=1-\frac{1}{C_{\mathrm{D}} M_{\mathrm{L}}}-\frac{1}{M_{\mathrm{d}}} .
\end{gathered}
$$

для процесса самодиффузии

$$
\begin{gathered}
D_{f}(0)=D_{\mathrm{d}}(\rho)_{0} \cdot x_{\mathrm{d}}(0), \quad D_{\mathrm{d}}(\rho)_{0}=f_{\text {cor }} \cdot \frac{k_{\mathrm{B}} \Theta_{\mathrm{o}} c_{\mathrm{o}}(0)^{2}}{2 \pi^{2} \hbar k_{\mathrm{p}}^{2 / 3}}, \\
\lim _{\frac{T}{\Theta_{0}} \rightarrow 0}\left(\frac{g_{\mathrm{d}}}{k_{\mathrm{B}}}\right)=M_{\mathrm{d}}-0.5 \ln \left(\frac{4 M_{\mathrm{d}}}{\pi}\right), \quad \lim _{\frac{T}{\Theta_{0}} \rightarrow 0}\left(\frac{h_{\mathrm{d}}}{k_{\mathrm{B}} T}\right)=0, \\
\lim _{\frac{T}{\Theta_{0}} \rightarrow 0}\left(\frac{s_{\mathrm{d}}}{k_{\mathrm{B}}}\right)=\frac{s_{\mathrm{d}}(0)}{k_{\mathrm{B}}}=-M_{\mathrm{d}}+0.5 \ln \left(\frac{4 M_{\mathrm{d}}}{\pi}\right), \\
\lim _{\frac{T}{\Theta_{0}} \rightarrow 0}\left(\frac{v_{\mathrm{d}}}{v_{\mathrm{a}}}\right)=\frac{v_{\mathrm{d}}(0)}{v_{\mathrm{a}}(0)}=0, \\
\lim _{\frac{T}{\Theta_{0}} \rightarrow 0}\left(\frac{v_{\mathrm{d}} B}{k_{\mathrm{B}} T}\right)=M_{\mathrm{d}} \cdot\left[\gamma_{\mathrm{o}}(0)-\frac{2}{3}\right] .
\end{gathered}
$$

Как следует из формул (21) и $(22)$, функции $s_{\mathrm{v}}(T)$ и $s_{\mathrm{d}}(T)$ положительны только при следующих условияX [55]:

$$
\begin{aligned}
& \left(\frac{k_{\mathrm{B}} T}{2 E_{\mathrm{L}}}\right) \ln \left(\frac{\pi E_{\mathrm{L}}}{k_{\mathrm{B}} T}\right)+\alpha_{P} T\left[\left(2-t_{y}\right) \gamma_{\mathrm{o}}-\frac{2}{3}\right] \geq t_{y}, \\
& \left(\frac{k_{\mathrm{B}} T}{2 E_{\mathrm{d}}}\right) \ln \left(\frac{4 E_{\mathrm{d}}}{\pi k_{\mathrm{B}} T}\right)+\alpha_{P} T\left[\left(2-t_{y}\right) \gamma_{\mathrm{o}}-\frac{2}{3}\right] \geq t_{y},
\end{aligned}
$$

Так как выполняется неравенство $E_{\mathrm{d}} / E_{\mathrm{L}}=C_{\mathrm{LD}}$ $=3 k_{n}^{\mathrm{o}} /\left(2 \pi^{2} k_{\mathrm{p}}^{2 / 3}\right)>1$, то равенство в условии (56) достигается при более низкой температуре $\left(T_{s \mathrm{~d}=0}\right)$, чем в условии (55) для положительности энтропии образования вакансии. Таким образом, при изобарическом нагреве соблюдается неравенство: $T_{s \mathrm{v}=0}>T_{s \mathrm{~d}=0}>0 \mathrm{~K}$.

Отметим, что Varotsos и Alexopoulos еще в 1979 г. показали в [56], что отрицательное значение энтропии образования вакансии $\left(s_{\mathrm{v}}<0\right)$ не противоречит термодинамическим условиям образования вакансии. Отрицательное значение энтропии образования вакансии при низких температурах экспериментально обнаружено у ОЦК- и ГПУ-модификаций кристаллов ${ }^{3} \mathrm{He}$ и ${ }^{4} \mathrm{He}$ в работах [57-61].

В работе [8] на примере алюминия теоретически показано, что если считать энтальпию образования вакансии зависимой от температуры, то энтропия образования вакансии получается отрицательной. В работе [62] при теоретическом изучении методом молекулярной динамики самодиффузии в ОЦК-Zr было показано, что ниже 
$600 \mathrm{~K}$ энтропия образования вакансии становится отрицательной. Таким образом, наш результат о переходе энтропии активационного процесса в отрицательную область при понижении температуры согласуется с экспериментальными и теоретическими работами других авторов, которые изучали активационные процессы при низких температурах.

Отметим, что наличие вакансий и D-атомов в кристалле при $T=0 \mathrm{~K}$ не нарушает третьего закона термодинамики, который гласит: удельная (на атом) энтропия кристалла при $T=0 \mathrm{~K}$ равна нулю: $s(T=0 \mathrm{~K})=0$. Из определения энтропии следует

$$
\begin{aligned}
s(T, P) & =-\left(\frac{\partial g}{\partial T}\right)_{P}=-\left(\frac{\partial g}{\partial T}\right)_{P, x_{\mathrm{d}}, \phi_{\mathrm{v}}} \\
& -\left(\frac{\partial g}{\partial \phi_{\mathrm{v}}}\right)_{P}\left(\frac{\partial \phi_{\mathrm{v}}}{\partial T}\right)_{P}-\left(\frac{\partial g}{\partial x_{\mathrm{d}}}\right)_{P}\left(\frac{\partial x_{\mathrm{d}}}{\partial T}\right)_{P} .
\end{aligned}
$$

где $g(T, P)$ - удельная (на атом) свободная энергия Гиббса кристалла.

Первое слагаемое в (57) представляет собой энтропию (на атом) кристалла, возникающую за счет изменения температуры при неизменной доле активационных параметров. В случае модели кристалла Эйнштейна первое слагаемое в (57) убывает при $T \rightarrow 0 \mathrm{~K}$ пропорционально зависимости $[14,18,19]: \exp (-\Theta / T)$. Второе и третье слагаемые в (57) представляют собой вклады в энтропию (на атом), возникающие только за счет изменения концентрации вакансий и D-атомов в кристалле. Как ясно видно из рис. 5 , при $T=0 \mathrm{~K}$ функции $\phi_{\mathrm{v}}(T)$ и $x_{\mathrm{d}}(T)$ имеют минимумы. Поэтому второе и третье слагаемые в (57) при $T=0 \mathrm{~K}$ также исчезают.

Поскольку объем активационного процесса при $T=0 \mathrm{~K}$ равен нулю, наличие вакансий и $\mathrm{D}$-атомов при $T=0 \mathrm{~K}$ не влияет на коэффициент теплового расширения кристалла.

Так как при $0 \mathrm{~K}<T<T_{s \mathrm{~d}=0}<T_{s \mathrm{v}=0}$ функции $s_{\mathrm{d}}(T)$ и $s_{\mathrm{v}}(T)$ имеют отрицательное значение, то здесь при изобарическом образовании в кристалле вакансии или D-атома происходит выделение тепла, равного $T s_{\mathrm{v}}$ или $T s_{\mathrm{d}}$, соответственно. Это согласуется с выводом, полученным в $[53,54]$ : при $T=0 \mathrm{~K}$ кристаллу энергетически выгоднее перейти в состояние, в котором часть узлов решетки вакантна, а часть атомов диффундирует по кристаллу. При $0<T<T_{s \mathrm{~d}=0}<T_{s v=0}$ делокализация атома, как и образование вакансии, приводит к „упорядочению“ решетки кристалла. Отметим, что это свойство - не прерогатива квантовых кристаллов. Оно присуще всем веществам, но наиболее заметно проявляется у кристаллов ${ }^{3} \mathrm{He}$ и ${ }^{4} \mathrm{He}$, ввиду относительно большой амплитуды „нулевых колебаний“ у атомов данных веществ.

При высоких температурах $\left(T / \Theta_{\text {Ео }}>2\right)$ можно принять $f_{y} \cong 1$ и $t_{y} \cong 0$. Поэтому в этой области температур энтропия активационного процесса всегда положительна. Возникающие в этих условиях вакансии и D-атомы переводят кристалл в более разупорядоченное состояние.
В заключение отметим, что в термодинамические определения активационных параметров (21) и (22) входят две функции: $\alpha_{P}-$ коэффициент теплового расширения и $B_{T}-$ модуль упругости. Функции эти неудобны тем, что имеют особенности при фазовом переходе первого рода (ФП-І), например, при фазовом переходе кристалл-жидкость (ФП К-Ж). В области бинодали S-петли ФП К-Ж функция $\alpha_{P}(T, V)$ терпит разрыв II рода, т. е. уходит в бесконечность. Это ведет к тому, что на бинодали ФП К-Ж получаем: $h_{\mathrm{v}}, s_{\mathrm{v}}, h_{\mathrm{d}}$ и $s_{\mathrm{d}} \rightarrow \infty$. С другой стороны, в точках спинодали S-петли ФП К-Ж выполняется $B_{T}=0$, а в межспинодальной области $B_{T}<0$. Это ведет к тому, что в точках спинодали функции $v_{\mathrm{v}}$ и $v_{\mathrm{d}}$ терпят разрыв II рода: $v_{\mathrm{v}}$ и $v_{\mathrm{d}} \rightarrow \infty$, а в межспинодальной области получается $v_{\mathrm{v}}$ и $v_{\mathrm{d}}<0$. В связи с этим аппарат равновесной и обратимой термодинамики не работает в области ФП К-Ж (как впрочем, и в области бинодали S-петли любого ФП-I) применительно к описанию активационного процесса: образования вакансий или самодиффузии. Поэтому поведение функций $h_{\mathrm{v}}, s_{\mathrm{v}}, v_{\mathrm{v}}, h_{\mathrm{d}}, s_{\mathrm{d}}$ и $v_{\mathrm{d}}$ в области ФП К-Ж до сих пор невозможно было оценить. В этом смысле метод расчета функций $\phi_{\mathrm{v}}(P, T)$ и $x_{\mathrm{d}}(P, T)$ из выражений $(10)-(19)$ имеет более широкую область применения. Это было показано в [21,22], при расчетах фазовой диаграммы аргона.

\section{9. Выводы}

1. Разработан аналитический метод для расчета зависимости активационных параметров в кристалле однокомпонентного вещества от давления и температуры.

2. Метод апробирован для ГЦК-кристалла золота при расчетах температурной зависимости активационных параметров вдоль двух изобар: $P=0$ и $24 \mathrm{GPa}$. Получено хорошее согласие с известными из литературы, как экспериментальными, так и теоретическими оценками.

3. Показано что при низких температурах $(T<\Theta)$ зависимость активационных параметров от температуры очень существенная, что обусловлено квантовыми эффектами. При высоких температурах $(T>\Theta)$ зависимость активационных параметров от температуры ослабляется и имеет почти линейный характер.

4. Показано, что энтропия активационных процессов возрастает с температурой, переходя при $T \gg \Theta$ из области отрицательных значений в положительную область.

5. Показано, что при низких температурах использование уравнение Аррениуса для определения энергетических параметров, как для образования вакансии, так и для самодиффузии, не корректно. Для золота использование уравнения Аррениуса некорректно уже при $T<200 \mathrm{~K}$.

6. При изотермическом сжатии энергия Гиббса возрастает, а энтропия и объем активационного процесса 
уменьшаются на всем температурном интервале. Энтальпия активационного процесса возрастает с ростом давления только при высоких температурах, а ниже определенной температуры (индивидуальной для процесса образования вакансий и самодиффузии) энтальпия активационного процесса при изотермическом сжатии уменьшается.

7. Показано, что при $T=0 \mathrm{~K}$ термодинамические параметры активационного процесса достигают минимума: энергия Гиббса, энтальпия и объем активационного процесса становятся равными нулю, а минимум энтропии активационного процесса лежит в отрицательной области.

\section{Благодарности}

Автор выражает благодарность С.П. Крамынину, К.Н. Магомедову, Н.Ш. Газановой, 3.М. Сурхаевой и М.М. Гаджиевой за плодотворные дискуссии и помощь в работе.

\section{Финансирование работы}

Работа выполнена при финансовой поддержке РФФИ (грант № 18-29-11013_мк).

\section{Конфликт интересов}

Автор заявляет, что у него нет конфликта интересов.

\section{Список литературы}

[1] Y. Kraftmakher. Phys. Rep. 299, 2-3, 79 (1998). DOI: $10.1016 / \mathrm{S} 0370-1573(97) 00082-3$

[2] Дж. Маннинг. Кинетика диффузии атомов в кристаллах. Мир, М. (1971). 278 c. [J.R. Manning, Diffusion Kinetics for Atoms in Crystals. D. Van Nostrand Comp., Toronto (1968). $257 \mathrm{p}$.]

[3] Б.С. Бокштейн, А.Б. Ярославцев. Диффузия атомов и ионов в твердых телах. Изд-во МИСиС, М. (2005). 362 с.

[4] P.A. Varotsos, K.D. Alexopoulos. Thermodynamics of point defects and their relation with bulk properties. Elsevier, Amsterdam, North Holland (2013). 489 p.

[5] G. Neumann, C. Tuijn. Self-diffusion and impurity diffusion in pure metals: handbook of experimental data. Pergamon/Elsevier, Boston (2009). 349 p.

[6] C. Freysoldt, B. Grabowski, T. Hickel, J. Neugebauer, G. Kresse, A. Janotti, C.G. Van de Walle. First-principles calculations for point defects in solids. Rev. Mod. Phys. 86, 1, 253 (2014). DOI: 10.1103/RevModPhys.86.253

[7] H. Mehrer. The effect of pressure on diffusion. Defect and Diffusion Forum 129-130, 57 (1996). DOI: 10.4028/www.scientific.net/DDF.129-130.57

[8] Н.П. Кобелев, В.А. Хоник. ЖЭТФ 153, 3, 409 (2018). DOI: 10.7868/S0044451018030070 [N.P. Kobelev, V.A. Khonik. J. Exp. Theor. Phys. 126, 3, 340 (2018). DOI: $10.1134 / \mathrm{S} 1063776118030032]$

[9] G. Smirnov. Phys. Rev. B 102, 18, 184110 (2020). DOI: $10.1103 /$ PhysRevB.102.184110
[10] P.-W. Ma, S.L. Dudarev. Phys. Rev. Mater. 3, 6, 063601 (2019). DOI: 10.1103/physrevmaterials.3.063601

[11] М.Н. Магомедов. ФТП 42, 10, 1153 (2008). [M.N. Magomedov. Semiconductors 42, 10, 1133 (2008)]. DOI: $10.1134 /$ S1063782608100011

[12] М.Н. Магомедов. Изучение межатомного взаимодействия, образования вакансий и самодиффузии в кристаллах. Физматлит, М. (2010). 544 с. [M.N. Magomedov, Study of Interatomic Interaction, Vacancy Formation and Self-Diffusion in Crystals. Fizmatlit, Moscow (2010)].

[13] Справочник по специальным функциям / Под ред. М. Абрамовица и И. Стиган. Наука, М. (1979). 832 с. [Handbook of Mathematical Functions / Eds M. Abramowitz, I. Stegun. National Bureau of Standards, N.Y. (1964). 1046 p.] https://www.math.hkbu.edu.hk/support/aands/intro.htm

[14] Р. Фейнман, Статистическая механика. Мир, М. (1978). 408 c. [R.P. Feynman, Statistical Mechanics. W.A. Benjamin Inc., Massachusetts (1972). 354 p.]

[15] А.Г. Чирков, А.Г. Пономарев, В.Г. Чудинов. ЖТФ 74, 2, 62 (2004). [A.G. Chirkov, A.G. Ponomarev, V.G. Chudinov. Tech. Phys. 49, 2, 203 (2004).] DOI: 10.1134/1.1648956

[16] Г.М. Полетаев, М.Д. Старостенков. ФТТ 51, 4, 686 (2009). [G.M. Poletaev, M.D. Starostenkov. Phys. Solid State 51, 4, 727 (2009).] DOI: 10.1134/S106378340904012X

[17] М.Н. Магомедов. ФТП 44, 3, 289 (2010). [M.N. Magomedov. Semiconductors 44, 3, 271 (2010).] DOI: $10.1134 / \mathrm{S} 1063782610030012$

[18] Э.А. Мелвин-Хьюз. Физическая химия. Изд-во ИЛ, М. (1962). 1148 c. [E.A. Moelwyn-Hughes. Physical Chemistry. Pergamon Press, London (1961). 1333 p.]

[19] Л. Жирифалько. Статистическая физика твердого тела. Мир, М. (1975). 382 c. [L.A. Girifalco. Statistical Physics of Materials. J. Wiley \& Sons Ltd, N. Y. (1973). 346 p.]

[20] М.Н. Магомедов. Физика металлов и металловедение 114, 3, 227 (2013). [M.N. Magomedov. Phys. Met. Metallography 114, 3, 207 (2013).] DOI: 10.1134/S0031918X13030113

[21] M.N. Magomedov. J. Mol. Liquids 285, 106 (2019). DOI: 10.1016/j.molliq.2019.04.032

[22] М.Н. Магомедов. ФТТ 63, 7, 966 (2021). DOI: 10.21883/FTT.2021.07.51050.272 [M.N. Magomedov. Phys. Solid State 63, 7, 1111 (2021). DOI: $10.1134 / \mathrm{S} 1063783421070167]$

[23] М.Н. Магомедов. Письма в ЖТФ 28, 10, 64 (2002). [M.N. Magomedov. Tech. Phys. Lett. 28, 5, 430 (2002).] DOI: $10.1134 / 1.1482758$

[24] М.Н. Магомедов. ЖТФ 83, 9, 56 (2013). [M.N. Magomedov. Tech. Phys. 58, 9, 1297 (2013).] DOI: $10.1134 / \mathrm{S} 106378421309020 \mathrm{X}$

[25] М.Н. Магомедов. ЖТФ 83, 12, 87 (2013). [M.N. Magomedov. Tech. Phys. 58, 12, 1789 (2013).] DOI: $10.1134 / \mathrm{S} 1063784213120153$

[26] М.H. Магомедов. ФТТ 63, 2, $191 \quad$ (2021). DOI: 10.21883/FTT.2021.02.50462.209 [M.N. Magomedov. Phys. Solid State 63, 215 (2021). DOI: $10.1134 / \mathrm{S} 1063783421020165]$

[27] М.H. Магомедов. ФТТ 62, 7, 998 (2020). DOI: $10.21883 /$ FTT.2020.07.49462.026 [M.N. Magomedov. Phys. Solid State 62, 7, 1126 (2020). DOI: $10.1134 /$ S1063783420070136] 
[28] М.Н. Магомедов. ФТТ 63, 9, $1415 \quad$ (2021). DOI: 10.21883 /FTT.2021.09.51279.080 [M.N. Magomedov. Phys. Solid State 63, 9, 1595 (2021). DOI: $10.1134 / \mathrm{S} 1063783421090250]$

[29] M. Matsui. J. Phys.: Conf. Ser. 215, 1, 012197 (2010). DOI: $10.1088 / 1742-6596 / 215 / 1 / 012197$

[30] W.B. Holzapfel, M. Hartwig, W. Sievers. J. Phys. Chem. Reference Data 30, 2, 515 (2001). DOI: 10.1063/1.1370170

[31] S.M. Collard, R.B. Mc Lellan. Acta Metallurgica Mater. 39, 12, 3143 (1991). DOI: 10.1016/0956-7151(91)90048-6

[32] T. Tsuchiya. J. Geophys. Res. 108, B10, 2462 (2003). DOI: $10.1029 / 2003 J B 002446$

[33] M.G. Pamato, I.G. Wood, D.P. Dobson, S.A. Hunt, L. Vočadlo. J. Appl. Crystallogr. 51, 2, 470 (2018). DOI: $10.1107 / \mathrm{S} 1600576718002248$

[34] S.M. Makin, A.H. Rowe, A.D. Leclaire. Proc. Phys. Soc. Section B 70, 6, 545 (1957). DOI: $10.1088 / 0370-1301 / 70 / 6 / 301$

[35] H.M. Gilder, D. Lazarus. J. Phys. Chem. Solids 26, 12, 2081 (1965). DOI: 10.1016/0022- 3697(65)90250-7

[36] E.W. Hart. Acta Metallurgica 5, 10, 597 (1957). DOI: 10.1016/0001-6160(57)90127-x

[37] H.M. Morrison, V.L.S. Yuen. Canadian J. Physics 49, 21, 2704 (1971). DOI: 10.1139/p71-326

[38] W. Xing, P. Liu, X. Cheng, H. Niu, H. Ma, D. Li, Y. Li, X.-Q. Chen. Phys. Rev. B 90, 14, 144105 (2014). DOI: $10.1103 /$ PhysRevB.90.144105

[39] B. Medasani, M. Haranczyk, A. Canning, M. Asta. Comput. Mater. Sci. 101, C, 96 (2015). DOI: $10.1016 /$ j.commatsci.2015.01.018

[40] Р.А. Кончаков, А.С. Макаров, А.С. Аронин, Н.П. Кобелев, В.А. Хоник. Письма в ЖЭТФ 113, 5, 341 (2021). DOI: $10.31857 / \mathrm{S} 1234567821050086$ [R.A. Konchakov, A.S. Makarov, A.S. Aronin, N.P. Kobelev, V.A. Khonik. J. Exp. Theor. Phys. Lett. 113, 5, 345 (2021). DOI: $10.1134 / \mathrm{S} 0021364021050064]$

[41] P. Varotsos, K. Alexopoulos. Phys. Rev. B 15, 8, 4111 (1977). DOI: $10.1103 /$ PhysRevB.15.4111

[42] W. Bollmann, N.F. Uvarov, E.F. Hairetdinov. Cryst. Res. Technol. 24, 4, 422 (1989). DOI: 10.1002/crat.2170240418

[43] R.H. Dickerson, R.C. Lowell, C.T. Tomizuka. Phys. Rev. 137, 2A, A613 (1965). DOI: 10.1103/physrev.137.a613

[44] R.M. Emrick. Phys. Rev. B 22, 8, 3563 (1980). DOI: 10.1103/PhysRevB.22.3563

[45] P. Varotsos, W. Ludwig, K. Alexopoulos. Phys. Rev. B 18, 6, 2683 (1978). DOI: 10.1103/PhysRevB.18.2683

[46] G.J. Ackland, G. Tichy, V. Vitek, M.W. Finnis. Phil. Mag. A56, 6, 735 (1987). DOI: 10.1080/01418618708204485

[47] P.A. Korzhavyi, I.A. Abrikosov, B. Johansson, A. Ruban, H.L. Skriver. Phys. Rev. B 59, 18, 11693 (1999). DOI: 10.1103/PhysRevB.59.11693

[48] P. Knorr, J. Jun, W. Lojkowski, C. Herzig. Phys. Rev. B 57, 1, 334 (1998). DOI: 10.1103/physrevb.57.334

[49] S. Mukherjee, R.E. Cohen, O. Gülseren. J. Phys.: Condens. Matter 15, 6, 855 (2003). DOI: 10.1088/0953-8984/15/6/312

[50] M. Senoo, H. Mii, I. Fujishiro, T. Takeuchi. Jpn J. Appl. Phys. 12, 10, 1621 (1973). DOI: 10.1143/JJAP.12.1621

[51] T.D. Cuong, A.D. Phan. Vacuum 179, 109444 (2020). DOI: 10.1016/j.vacuum.2020.109444

[52] М.Н. Магомедов. Письма в ЖТФ 27, 18, 36 (2001). [M.N. Magomedov. Tech. Phys. Lett. 27, 9, 773 (2001).] DOI: $10.1134 / 1.1407355$
[53] А.Ф. Андреев, И.М. Лифшиц. ЖЭТФ 56, 6, 2057 (1969). [A.F. Andreev, I.M. Lifshitz. Sov. J. Exp. Theor. Phys. 29, 6, 1107 (1969).] DOI: 10.1070/PU1971v013n05ABEH004235

[54] A.F. Andreev. Prog. Low Temperature Phys. 8, 67 (1982). DOI: $10.1016 / \mathrm{s} 0079-6417(08) 60005-0$

[55] М.Н. Магомедов. Письма в ЖТФ 34, 10, 20 (2008). [M.N. Magomedov. Tech. Phys. Lett. 34, 5, 414 (2008).] DOI: $10.1134 / \mathrm{S} 1063785008050167$

[56] P. Varotsos, K. Alexopoulos. J. Phys. C 12, 19, L761 (1979). DOI: 10.1088/0022-3719/12/19/004

[57] S.M. Heald, D.R. Baer, R.O. Simmons. Phys. Rev. B 30, 5, 2531 (1984). DOI: 10.1103/PhysRevB.30.2531

[58] P.R. Granfors, B.A. Fraass, R.O. Simmons. J. Low Temperature Phys. 67, 5/6, 353 (1987). DOI: $10.1007 / \mathrm{BF} 00710349$

[59] I. Iwasa, H. Suzuki. J. Low Temperature Phys. 62, 1/2, 1 (1986). DOI: 10.1007/BF00681316

[60] I. Iwasa. J. Phys. Soc. Jpn 56, 5, 1635 (1987). DOI: 10.1143/JPSJ.56.1635

[61] M.E.R. Bernier, J.H. Hetherington. Phys. Rev. B 39, 16, 11285 (1989). DOI: 10.1103/PhysRevB.39.11285

[62] M.I. Mendelev, B.S. Bokstein. Phil. Mag. 90, 5, 637 (2010). DOI: $10.1080 / 14786430903219020$

Редактор Е.В. Толстякова 